\title{
Article
}

\section{Expression and pharmacological inhibition of TrkB and EGFR in glioblastoma}

Pinherio, Kelly V, Thomaz, Amanda, Kunler Souza, Barbara, Metcalfe, Victoria Anne, Hogetop Freire, Natalia, Tesainer Brunetto, Andre, Brunette de Farias, Caroline, Jaegar, Mariane, BambiniJunior, Victorio, Smith, Christopher George severin, Shaw, Lisa and Roesler, Rafael

Available at http://clok.uclan.ac.uk/34652/

Pinherio, Kelly V, Thomaz, Amanda, Kunler Souza, Barbara, Metcalfe, Victoria Anne, Hogetop Freire, Natalia, Tesainer Brunetto, Andre, Brunette de Farias, Caroline, Jaegar, Mariane, Bambini-Junior, Victorio ORCID: 0000-0002-85906770 et al (2020) Expression and pharmacological inhibition of TrkB and EGFR in glioblastoma. Molecular Biology Reports, 47 . pp. 6817-6828. ISSN 03014851

It is advisable to refer to the publisher's version if you intend to cite from the work. http://dx.doi.org/10.1007/s11033-020-05739-2

For more information about UCLan's research in this area go to http://www.uclan.ac.uk/researchgroups/ and search for < name of research Group>.

For information about Research generally at UCLan please go to http://www.uclan.ac.uk/research/

All outputs in CLoK are protected by Intellectual Property Rights law, including Copyright law. Copyright, IPR and Moral Rights for the works on this site are retained by the individual authors and/or other copyright owners. Terms and conditions for use of this material are defined in the policies page.

\section{CLoK}

Central Lancashire online Knowledge www.clok.uclan.ac.uk

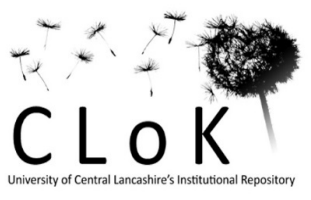




\section{Molecular Biology Reports \\ Expression and pharmacological inhibition of TrkB and EGFR in glioblastoma \\ --Manuscript Draft--}

Manuscript Number:

Full Title:

Article Type:

Keywords:

\section{Corresponding Author:}

Corresponding Author Secondary Information:

Corresponding Author's Institution:

Corresponding Author's Secondary Institution:

\section{First Author:}

First Author Secondary Information:

Order of Authors:

Funding Information:
MOLE-D-20-00758R1

Expression and pharmacological inhibition of TrkB and EGFR in glioblastoma

Original Article

Brain tumor; Epidermal Growth Factor Receptor; glioblastoma; Growth factor receptor; Neurotrophin; Tropomyosin receptor kinase B

Rafael Roesler, PhD

Federal University of Rio Grande do Sul

Porto Alegre, RS BRAZIL

Federal University of Rio Grande do Sul

Kelly de Vargas Pinheiro, PhD

Kelly de Vargas Pinheiro, PhD

Amanda Thomaz, PhD

Bárbara Kunzler Souza, PhD

Victoria Anne Metcalfe

Natália Hogetop Freire

André Tesainer Brunetto, MD

Caroline Brunetto de Farias, PhD

Mariane Jaeger, PhD

Victorio Bambini, PhD

Christopher G.S. Smith, PhD

Lisa Shaw, PhD

Rafael Roesler, PhD

National Council for Scientific and Technological Development (CNPq)

Dr Rafael Roesler (305647/2019-9)

National Council for Scientific and Dr Rafael Roesler

Technological Development (CNPq)

(409287/2016-4)

Coordination for the Improvement of Not applicable Higher Education Personnel (CAPES)

Children's Cancer Institute (ICI)

Not applicable

Clinical Hospital institutional research fund Not applicable (FIPE/HCPA)

University of Central Lancashire Not applicable

InbetweenEars Not applicable

Brain Tumour North West Research Not applicable

Consortium 


\begin{tabular}{|c|c|}
\hline Abstract: & $\begin{array}{l}\text { Background: A member of the Trk family of neurotrophin receptors, tropomyosin } \\
\text { receptor kinase B (TrkB, encoded by the NTRK2 gene) is an increasingly important } \\
\text { target in various cancer types, including glioblastoma (GBM). EGFR is among the most } \\
\text { frequently altered oncogenes in GBM, and EGFR inhibition has been tested as an } \\
\text { experimental therapy. Functional interactions between EGFR and TrkB have been } \\
\text { demonstrated. In the present study, we investigated the role of TrkB and EGFR, and } \\
\text { their interactions, in GBM. } \\
\text { Methods and Results: Analyses of NTRK2 and EGFR gene expression from The } \\
\text { Cancer Genome Atlas (TCGA) datasets showed an increase in NTRK2 expression in } \\
\text { the proneural subtype of GBM, and a strong correlation between NTRK2 and EGFR } \\
\text { expression in glioma CpG island methylator phenotype (G-CIMP+) samples. We } \\
\text { showed that when TrkB and EGFR inhibitors were combined, the inhibitory effect on } \\
\text { A172 human GBM cells was more pronounced than when either inhibitor was given } \\
\text { alone. When U87MG GBM cells were xenografted into the flank of nude mice, tumor } \\
\text { growth was delayed by treatment with TrkB and EGFR inhibitors, given alone or } \\
\text { combined, only at specific time points. Intracranial GBM growth in mice was not } \\
\text { significantly affected by drug treatments. } \\
\text { Conclusions: Our findings indicate that correlations between NTRK2 and EGFR } \\
\text { expression occur in specific GBM subgroups. Also, our results using cultured cells } \\
\text { suggest for the first time the potential of combining TrkB and EGFR inhibition for the } \\
\text { treatment of GBM. }\end{array}$ \\
\hline
\end{tabular}


Response to reviews

Manuscript number: \#MOLE-D-20-00758

Entitled: "Expression and pharmacological inhibition of TrkB and EGFR in glioblastoma"

First author: Kelly V. Pinheiro

Corresponding author: Rafael Roesler

\section{COMMENTS FROM EDITOR:}

We notice that the journal guidelines were not fully followed in the original version of the manuscript namely regarding the Abstract format and the number of figures (make use of supplementary figures as necessary).

Response: We have now revised the Abstract and number of figures according to the journal guidelines. Figure 6 has become Supplementary Figure $S 1$ in the revised manuscript.

\section{REVIEWER \#1}

1. Reviewer's comment: The authors explore the hypothesis of a potential interaction between TrkB and EGFR in glioblastoma in which both tyrosine kinase 
receptors have been implicated. Because TrkB and EGFR are known to functionally interact, the authors tested whether combining TrkB and EGFR inhibition, using respectively ANA12 and AG1478, may potentiate their respective effects when applied alone. Although the authors found no correlation between TrkB and EGFR expressions in glioblastoma using The Cancer Genome Atlas dataset, they found that co-inhibition of both receptors led to increased effects on the viability of cultured A172 cells (a model of human glioblastoma). However these findings could not be reproduced wit another cell line (U87MG cells). The authors performed a pharmacological interaction analysis using the Chou-Talalay method to find synergism between the two drugs in A172 cells, but antagonism in U87MG cells. To my opinion, these surprising results are very interesting and would have merited more attention/discussion. This point should be, at the very least, be addressed in the discussion section.

Response: We thank the Reviewer for the thoughtful comment. Although the mechanisms underlying this opposite pattern of effects remain unclear and it is difficult to hypothesize about it at this point, we have included a new paragraph in the Discussion section to address this issue (page 18). As stated in the revised manuscript, one possibility involves different EGFR receptors expressed in the two cell lines: U87 MG cells only express wild-type EGFR, whereas A172 cells also express mutant TDM/18-26 EGFR.

2. Reviewer's comment: Finally, the authors tested pharmacological interaction between the two drugs using glioblastoma xenograft in mice. However, although both ANA12 and AG1478 seemed to slow down the progression of tumor growth, no further potentiation could be observed when both drugs were combined. In 
addition, the previous beneficial effects of drugs alone that were observed during the course of the treatment were abolished at the end of the study. I have a major problem with this last part, which is most likely due to a poor experimental design rather than to a true biological effect.

Response: We acknowledge the limitations in this experiment. We were interested in verifying whether pretreatment of the cells before inoculation would be a suitable model for GBM growth and studying drug effects. We still think the data is worth of inclusion in the paper despite the less clear effects.

3. Reviewer's comment: As stated above, the differential effects observed between A172 and U87 cell lines is rather surprising and would merit some discussion. For instance, how do the authors explain the apparent switch in IC50 between both cell types for AG1478? Is it significant? For better clarity, mean +/SEM should be provided in the Table of Figure 3. Also, very intriguing to me is the switch from synergism to antagonism between the two drugs when they are combined in A172 or in U87 cells. Can the authors provide an explanation?

Response: As stated above, it is now unclear why we found contrasting effects between the two cell lines. However, further review of the literature showed us that U87 MG cells only express wild-type EGFR, whereas A172 cells also express mutant TDM/18-26 EGFR. We have included a new paragraph in the Discussion section to address this information, along with relevant new references (page 18). In addition, current literature recognizes that BDNF can play opposite actions depending on the cellular context. These differential effects may have to do with distinct isoforms of TrkB expressed in different tumors (Radin and Patel, 2017, 
"BDNF: an oncogene or tumor suppressor?", Anticancer Research 37: 39833990). The same dependency on cellular environment might be related to the switch to antagonism in the presence of the EGFR inhibitor. This issue is now discussed in the revised manuscript (page 18).

4. Reviewer's comment: I also have difficulties to understand how the authors calculated separate IC50s for ANA12 and AG1478 in Figure 3, when both drugs are combined? The apparent IC50 is for both drugs combined, it is not possible to distinguish one from the other. Can the authors explain this point?

Response: When IC50s are calculated using Graph Prisma, data can be plotted for each drug separately but IC50s are still calculated for the combined treatment when that is the case. Figure 3 has been revised for clarification.

5. Reviewer's comment: I have a real problem with the in vivo study. How were ANA12 and AG1478 doses and treatment regimen determined for the in vivo experiments? Do these doses correspond to their respective IC50s once they reach the xenograft? It is also very unlikely that the same dose reaches the intracranial tumor after crossing the BBB. Why did the authors use the same treatement for both types of xenograft? Also, does the treatement procedure lead to a stable presence of the drug overtime? In the discussion, the authors explain that these doses were determined based on previous studies but I failed to find any details in cited references. This point is critical for a good interpretation of the results since the drugs did not show satisfying effects in vivo, most likely because of inappropriate treatment procedure. In addition, because the number of animals 
is extremely low ( $n=8$ in Fig.5, $n=5$ in Fig.6), it is highly likely that the lack of apparent effect is due to the design of the study rather than to a biological effect. For all these reasons, I would suggest the authors to either remove the in vivo study or to provide more data and controls, including more mice per group and an analysis of drug efficiency at key time points (using Western Blots of pTrkB and $p E G F R$ for ex).

Response: Drug doses were chosen on the basis of previous studies using in vivo injections of ANA-12 and AG1478 in rats and mice. Both drugs readily enter the rodent brain when given systemically. This information along with appropriate references have now been clarified in the revised manuscript (pages 8 and 9 , references 20-25). We have not used the same doses for both in vivo models in the first in vivo experiment, the cells were pre-treated before inoculation. We agree that the in vivo results offer limited conclusions, and at the present time our laboratory is shut down due to the lockdown and we are not able to perform further experiments to increase the sample size or provide additional measures. We have thus followed the Reviewer's suggestion and removed the final in vivo experiment from the main article, changing Figure 6 to a Supplemental Figure.

6. Reviewer's comment: The figures are of low quality, which makes the text on graphs difficult to read.

Response: Figures have been improved in the revised manuscript.

7. Reviewer's comment: On page 14, line 19: shouldn't "reduction of S phase" be "increase of S phase" instead? 
Response: Yes, we thank the Review for pointing it out. That statement has been corrected in the revised manuscript.

8. Reviewer's comment: For better clarity, I would suggest to group results by cell cycle phases instead of doses in Figure 4.

Response: Figure 4 has been revised according to the Reviewer's suggestion.

9. Reviewer's comment: In Figure 5, the schematic drawing shows a 96-w plate while the text in the Method section indicates cultures in flasks. Similarly, the scheme shows xenograft in left flank while the text indicates right flank.

Response: Figure 5 has been modified in order to correct the informations regarding the use of flasks and xenografts in the right flank.

10. Reviewer's comment: In Figure 6, the initial number of mice is 5, but only 3 to 4 points are reported in the graphs. The authors should explain why individuals have been removed from the analysis.

Response: Figure 6 has been removed from the main article and is now presented as Supplementary Figure S1. In this figure we summarize the results from an early experiment using the low sample number of 4-5 mice per group mentioned. Subsets of these mice were used for imaging the whole brain and perform images from brains sections to improve the fluorescence detection as previously described (Theranostics 2018; 8(14):3991-4002. doi:10.7150/thno.23709). Unfortunately, we were not able to euthanize all 
animals on the same day in order to get data from all mice simultaneously. Moreover, mice that did not develop U87 tumors were removed from the study, resulting in a low sample size. Due to all these limitations, data shown in Supplementary Figure S1 should be taken as preliminary and illustrative. However, we still think it should made available as a supplementary figure to illustrate the technical aspects of this imaging approach.

\section{REVIEWER \#2}

1. Reviewer's comment: The logic for focusing, for instance, on the A172 cell line as a model is not quite acceptable. First, the authors postulate that Trkb and EGFR correlation is higher in LGG proneural GBM samples. No clear reasoning and mention of cell lines choices are given throughout the text. Furthermore, pieces of evidence in GBM literature of protein expression that define belonging of these cell lines to mesenchymal type, as well as the activity of several growth factor genes and extracellular matrix genes, were evaluated. Glioma cell lines, such as A172, vary in morphology and surface markers expression. High level of mesenchymal markers CD90 and CD105, fibroblast activation protein, and tenascin $C$ was detected for the $A 172$ cell line. Also, a high level of a2 smooth muscle actin gene. Data demonstrating high activity of genes encoding major angiogenesis inductors (VEGF, TGF $\beta 1$ ) and thrombospondin-1 in cell lines under study are in agreement with published data. Reduction of fetal serum content in culture medium from 10 to 5\% increased the number of cells with CD73 and CD105 surface antigens in both cell lines. A172 and U87MG cell lines maintain 
the main features of glioblastomas in early passages, and changes are definitely observed in late stages in culture.

Besides, we have to raise awareness on the reliability of GBM models and the identity crisis of one-dimensional cell lines. So authors must address this issue. Therefore, In vitro data with proneural-like GBM cell lines should be considered after data obtained on TCGA. In vivo studies considering the best phenotype might show a much more significant robust response to the combination of the receptors inhibitors. The choices are critical to making that link with GBM data from patients.

Response: The conclusion that TrkB and EGFR correlation is higher in LGG proneural GBM samples was obtained from gene expression data obtained from patient tumors from The Cancer Genome Atlas (TCGA $n=631$ samples) GBM and TCGA Lower Grade Glioma and Glioblastoma ( $\mathrm{n}=702$ samples) datasets, not from cell lines. The U87 cell line was chosen for in vivo experiments because of its tumorigenicity, and the A172 line has an overall similar biological profile when it comes to some important markers and mutations, according to the ATCC. However, it also expresses a mutant EGFR, which might partially explain the contrasting results we observed between the two cell lines in some assays (see page 18 in the revised manuscript). We acknowledge the limitations of cell lines as tumor models, but we think they were adequate for a first evaluation of the functional interactions between the receptor systems we studied. At this time it is not possible to replicate the experiments using other cell models. 
2. Reviewer's comment: No data available shows directly downstream signals (targets) blocked by the inhibitors. The authors must show the extension of these effects on those cell lines to be able to clarify the contradicting data on the synergism and antagonism, as well as the scarce effect in vivo. Western blottings and or other Protein assays for checking the activity of the main effectors of EGFR-and TrkB-stimulated pathways must be presented to further sustained the interpretation. Both cell cycle arrest and gene expression should be assessed in time and dose-response in vitro.

Response: We agree that our study has limitations and one can always suggest additional experiments that would improve any given study. The focus of this very first study examining functional interactions between TrkB and EGFR was to verify whether the combined treatment could affect outcomes related to cell proliferation and tumor growth. We hope the Reviewers and Editors understand that, given the current situation with the COVID-19 pandemic

3. Reviewer's comment: The lack of use of glioma stem cell lines in vivo and neurospheres in this study in vitro turned out to be relevant. Since authors can perform in vivo experiments, very elegantly, PDX cells and iPS models would contribute significantly to the raised questions. There are GSC cell databanks already clearly presenting the differences among GBM subtypes as relevant for drug resistance and tumor progression. Nevertheless, at this point, it is reasonable to invest in more consistent data from either tumor samples obtained herein and, again, in vitro protein assays. Therefore, to unveil whether inhibitors protocol was sufficient or adequate to be extrapolated in vivo with the used cell lines. In the same way, discussion on the tumoral microenvironment playing a 
more prominent role in the GBM tumor growth and susceptibility to pharmacological interventions are welcomed in this case.

Response: We agree with the excellent suggestions for additional experiments made by the Reviewers. Certainly, including comparisons with iPS cells, for example, would be highly valuable. Unfortunately, at this time it is not possible to carry out such complex additional experiments in time for inclusion in this revised manuscript. We agree with the excellent comment regarding tumor microenvironment and we have included a brief discussion on this topic along with relevant references (pages 18 and 19).

4. Reviewer's comment: Overall, the quality of the statistical analysis is high. The data is generally solid and the manuscript is clear. Nevertheless, since correlation is main outcome in this work, authors should consider the use of FDR values; it is not clear whether it is only a terminology issue throughout the manuscript.

Response: We thank the Reviewer's comment acknowledging the quality of our statistical analysis. When analyzing gene expression, we chose the method using $p$ values rather than FDR values, as an equally valid method.

5. Reviewer's comment: The conclusion made from the data in Figure 6 would be strengthened considerably by showing histopathology of the tumors. Many readouts from both simple H\&E staining and IHC specific markers are essential to speculate beyond the pharmacological inhibition in vitro. For instance, 
differences in Mitotic figures counting or Ki67 staining for the discussed cell cycle arresting would be more than incremental.

Response: Unfortunately, it is not possible to recover the tumors and perform further analyses at this time. As explained above, we acknowledge the limitations of the experiment shown in Figure 6. This figure has been removed from the main article and is now a supplementary figure. 


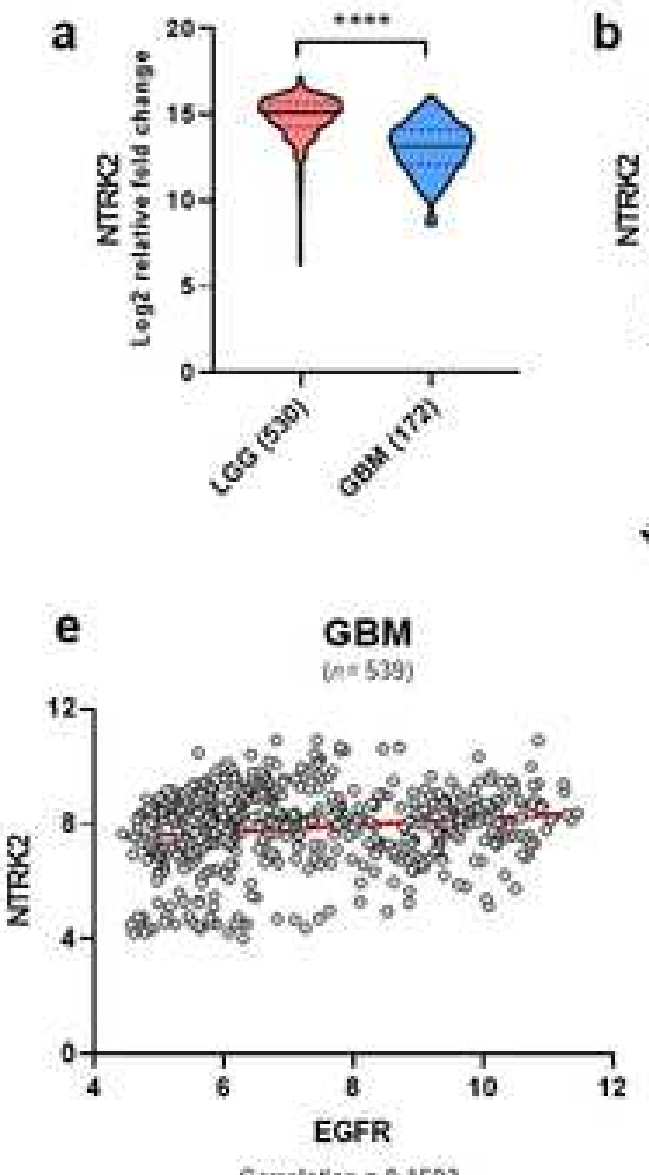

Correlatsen $=0.1603$ P-value $=00002$
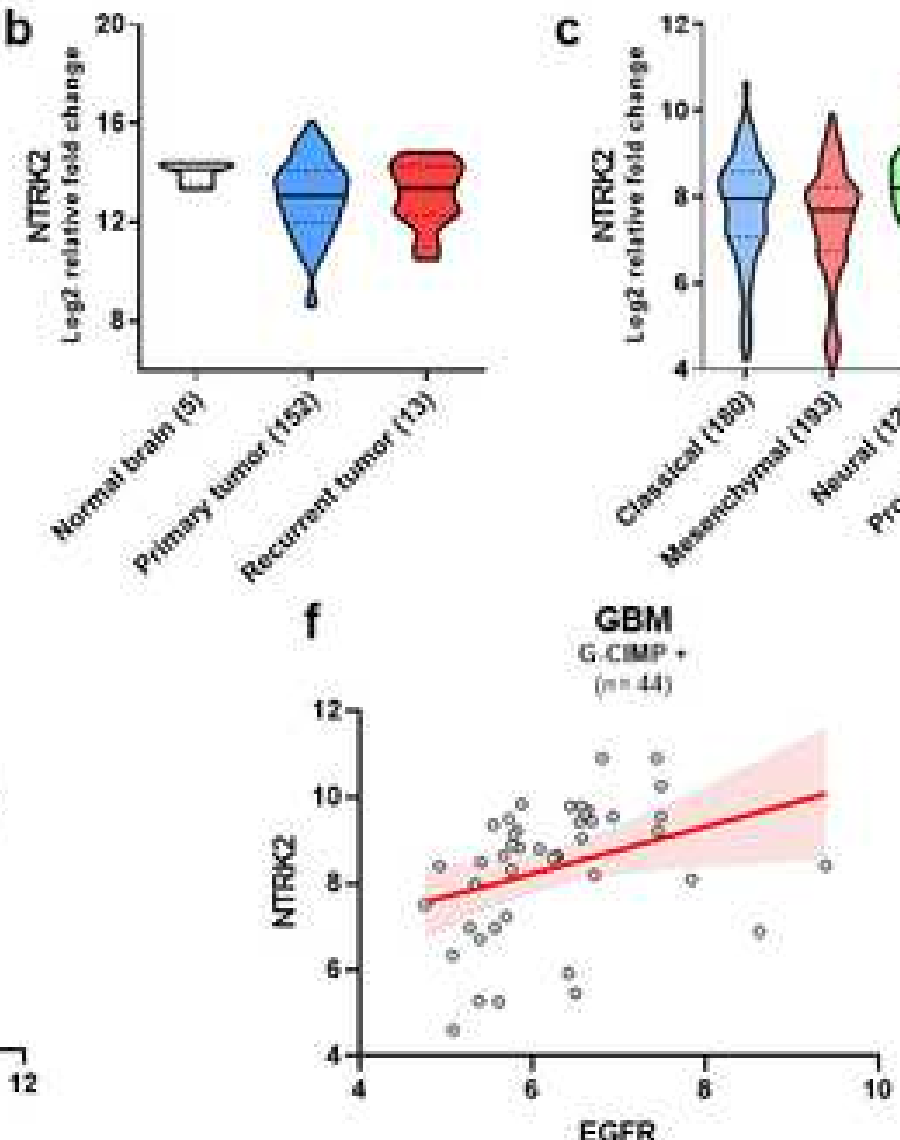

Corretation $* 0.3443$ Pivalue = 00221
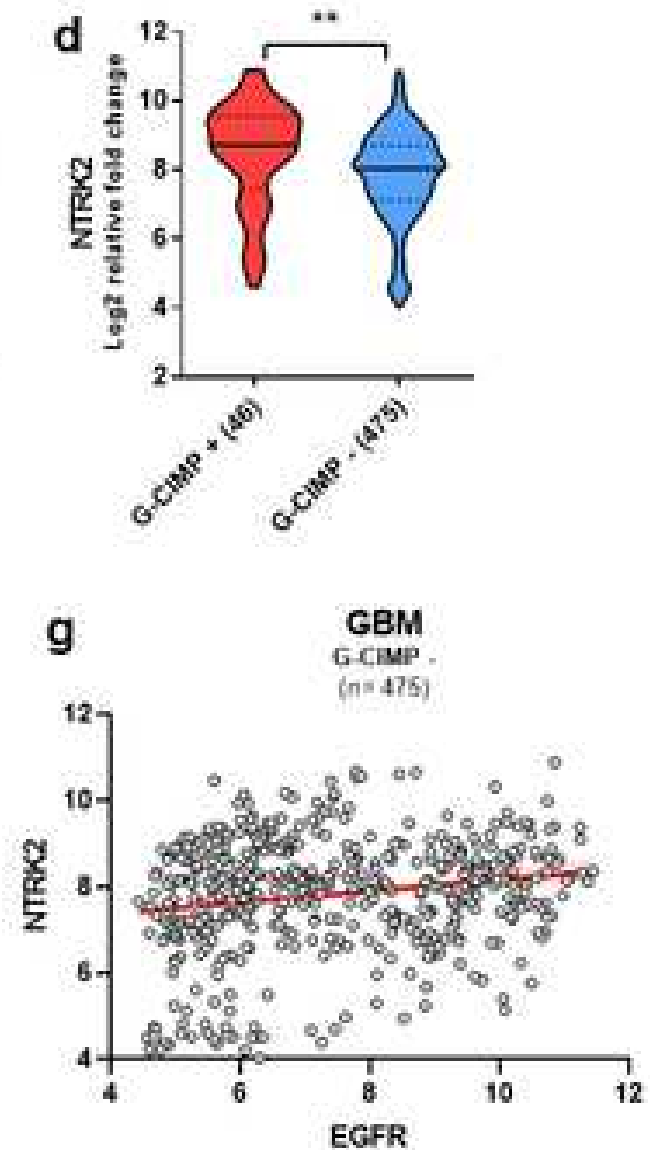

Conelation $=0.1359$ P.value $<0.0001$

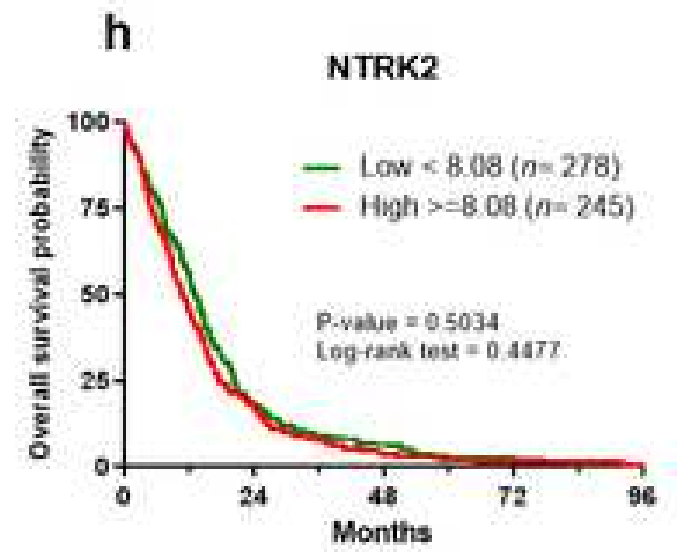

i

NTRK2

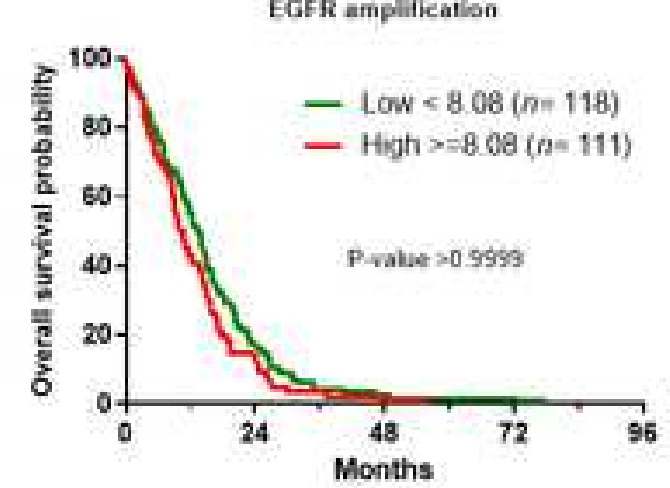

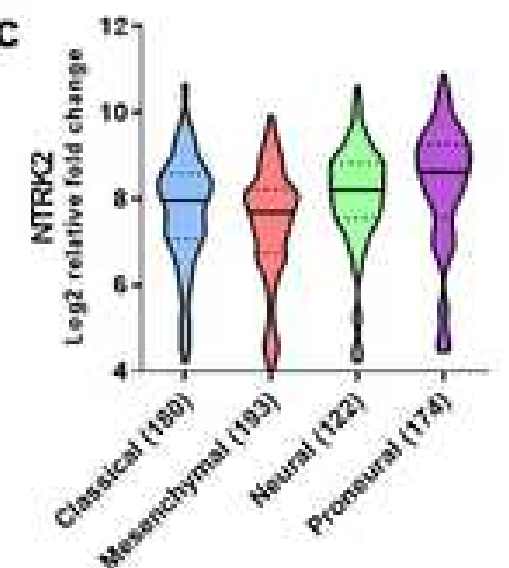




\section{A172}

a

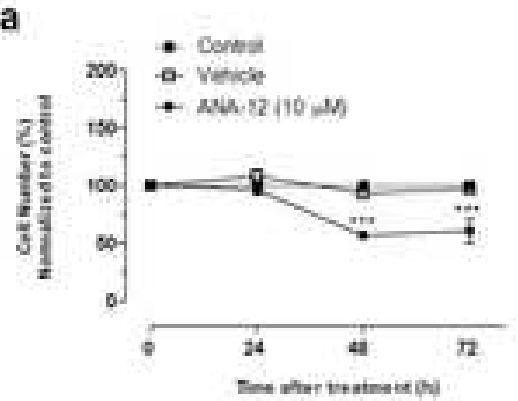

c

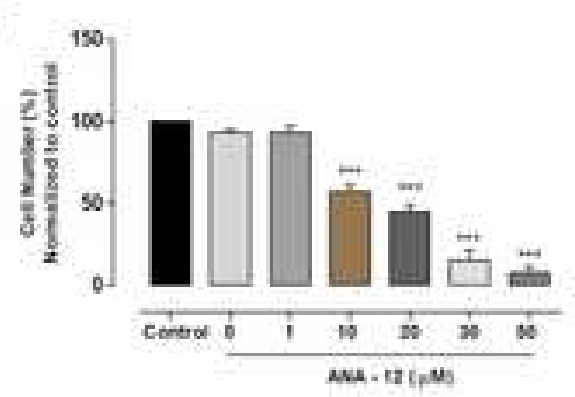

d
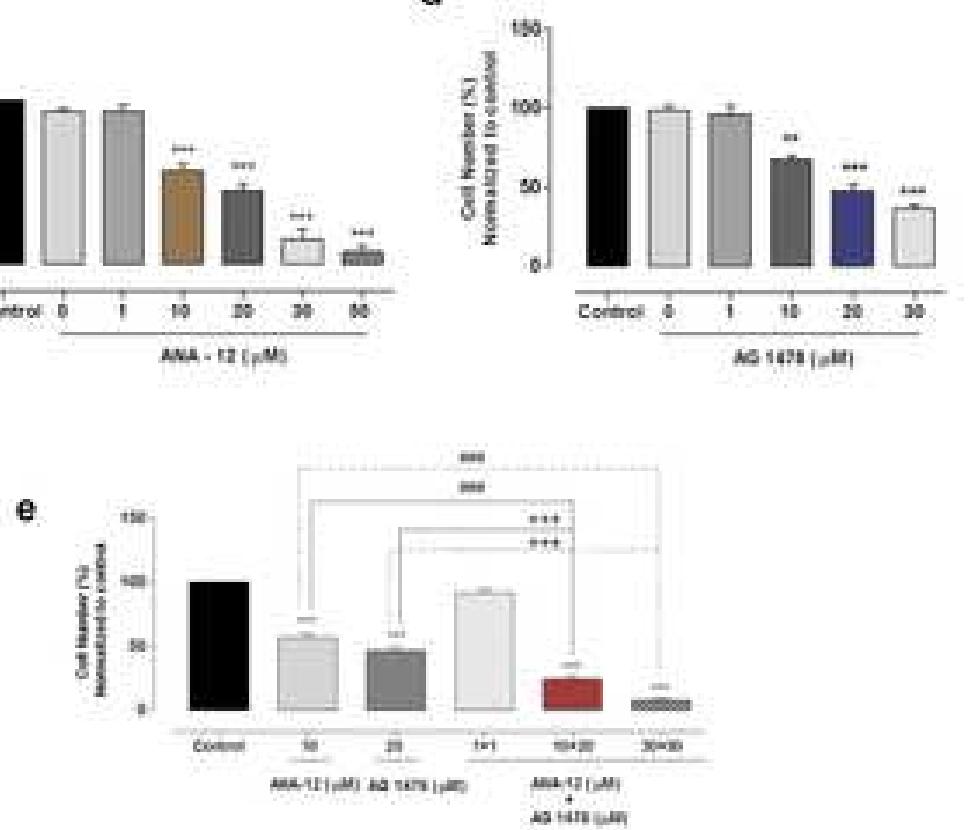

บ87

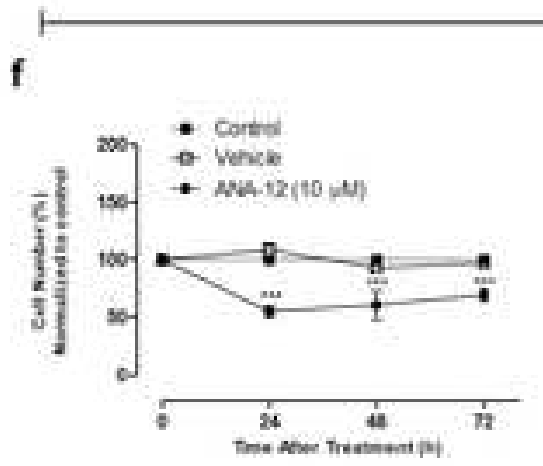

h

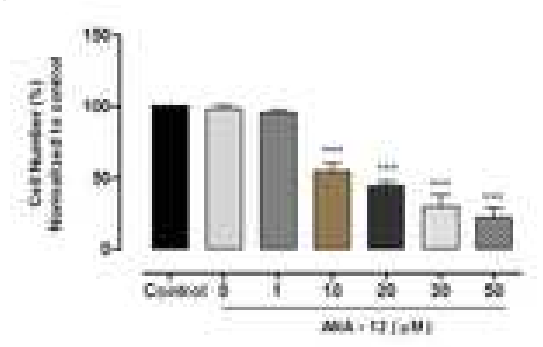

\section{g}

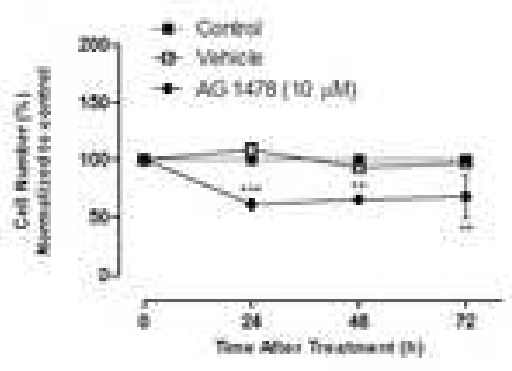

i

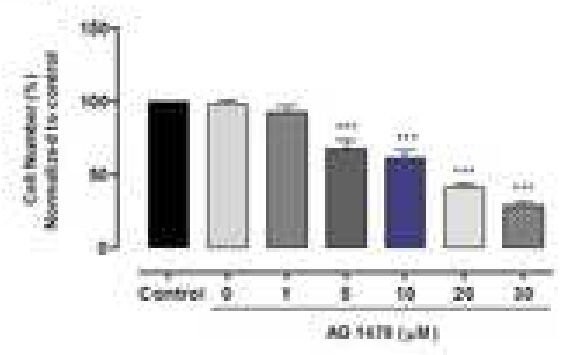

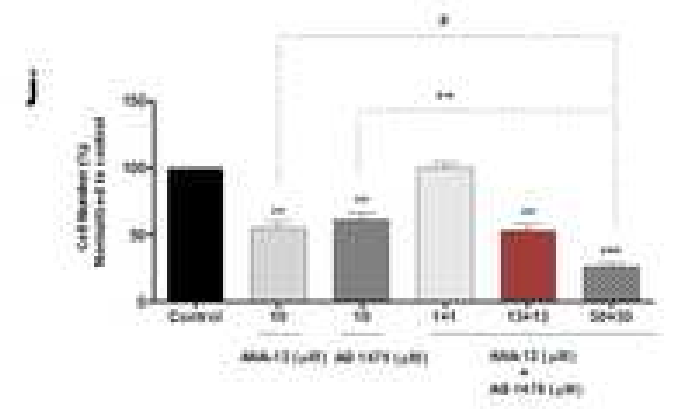


a

\begin{tabular}{|c|c|c|c|c|}
\hline Antagonists & $\begin{array}{c}\text { IC } 50(\mu \mathrm{M}) \\
\mathrm{A} 172\end{array}$ & Std. Error & $\begin{array}{c}\text { IC } 50(\mu M) \\
\text { U87 }\end{array}$ & Std. Error \\
\hline ANA-12 & $10.0(7-14)$ & 0.064 & $13.85(11-17)$ & 0.046 \\
\hline
\end{tabular}

b

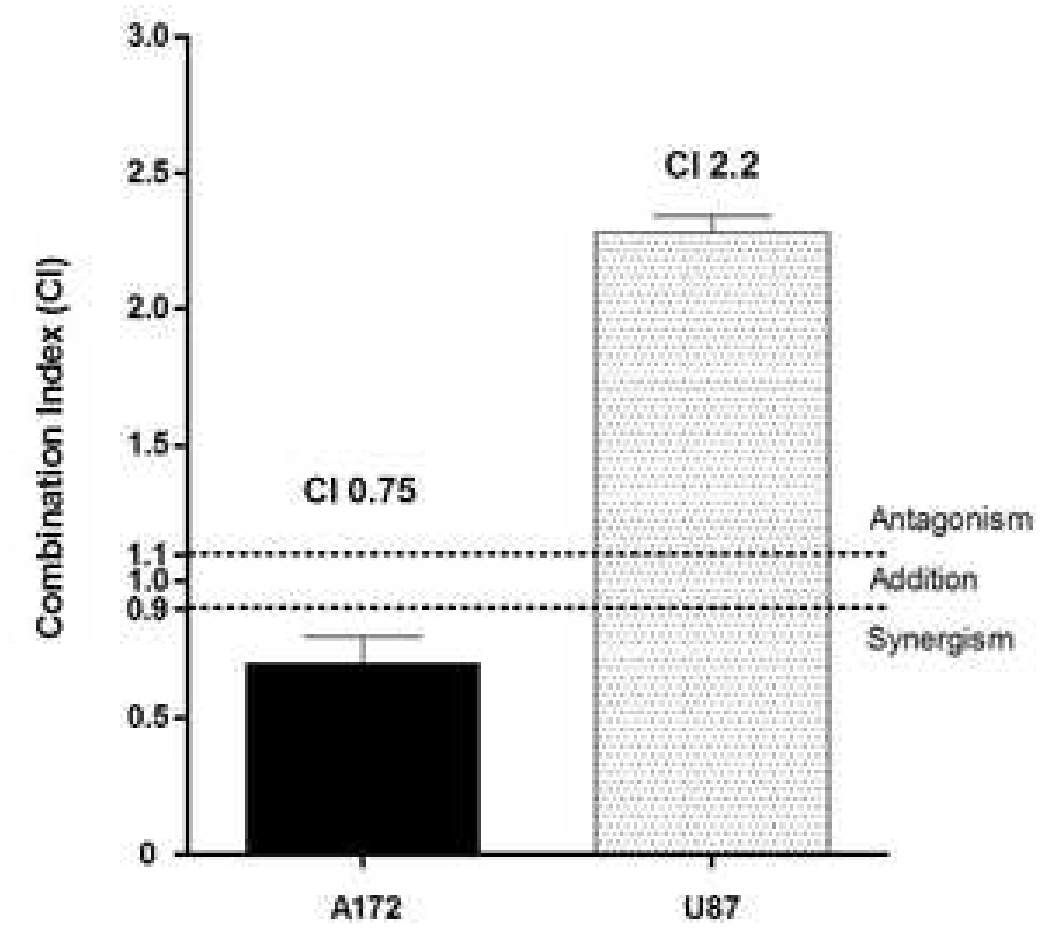
ANA-12+ AG 147 $(2-6)+6.70(5-8)$

U87 
A172

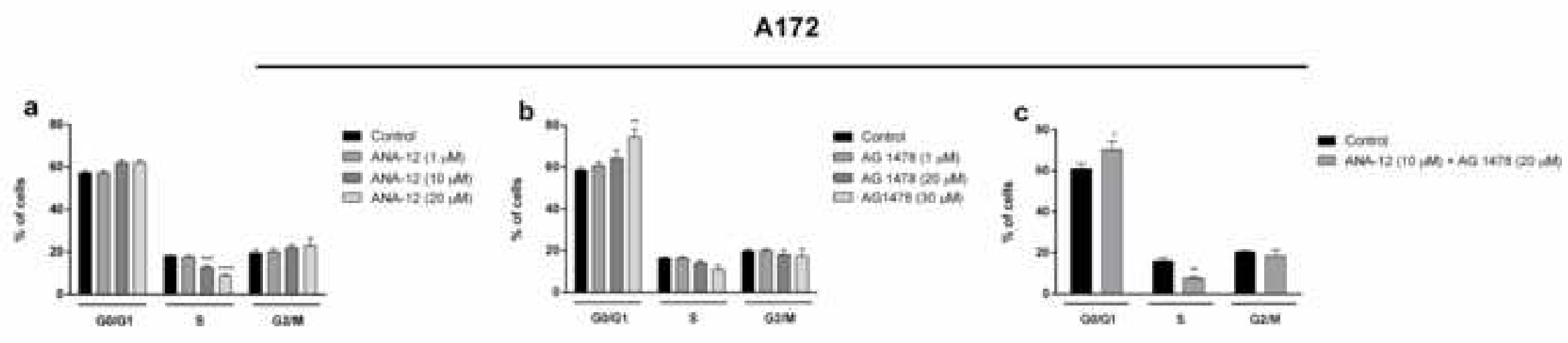

U87

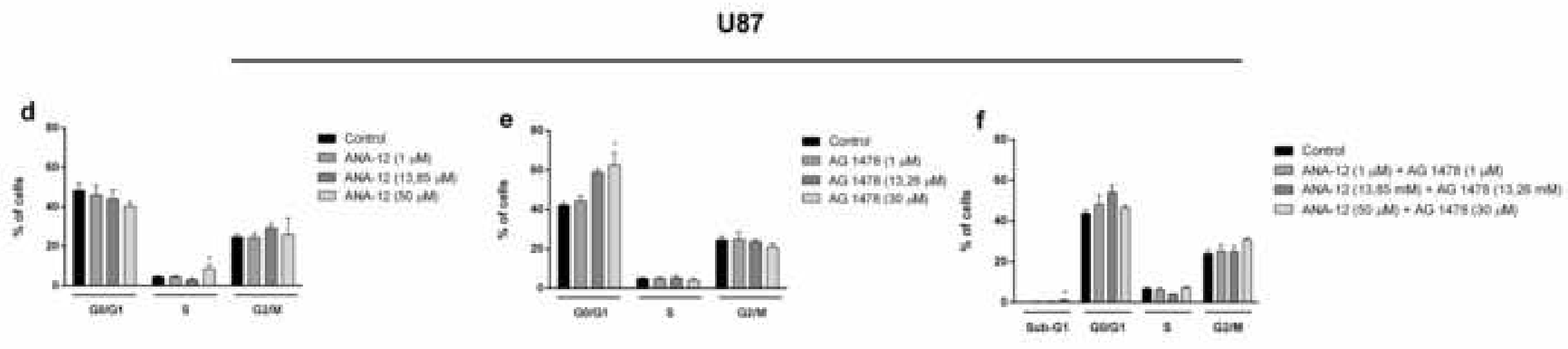




\section{a}

1. U⿺7 cells treatment (in viture)
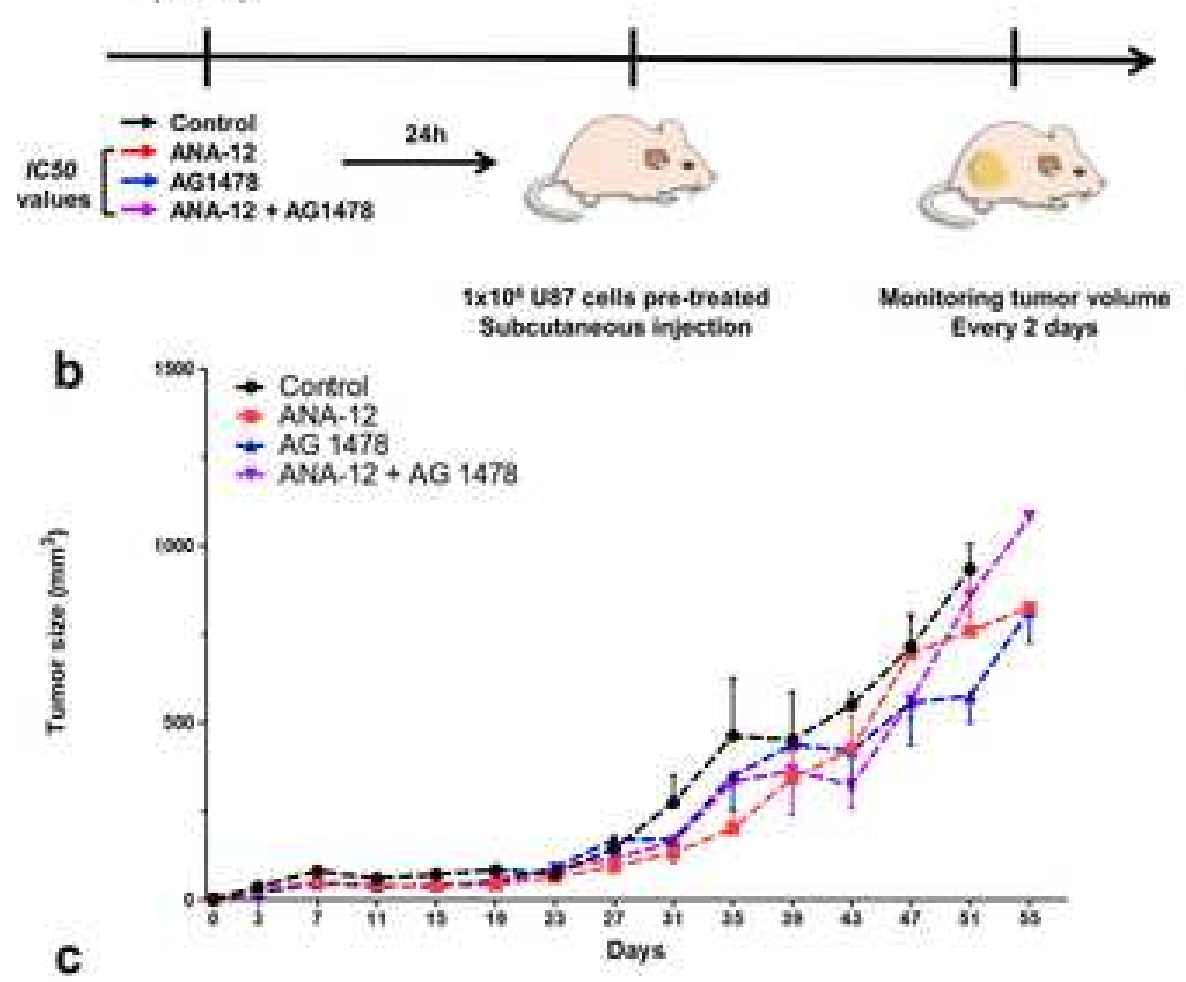

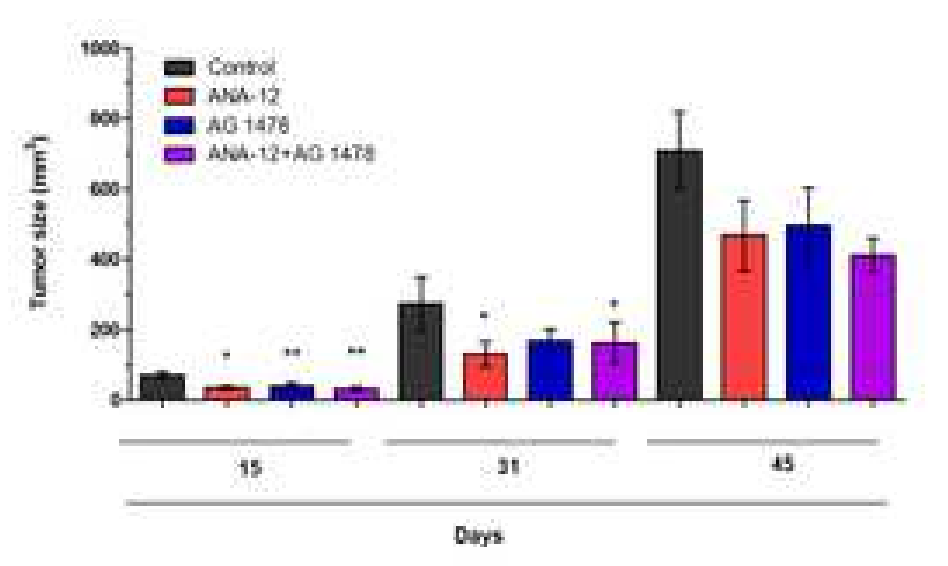

c d

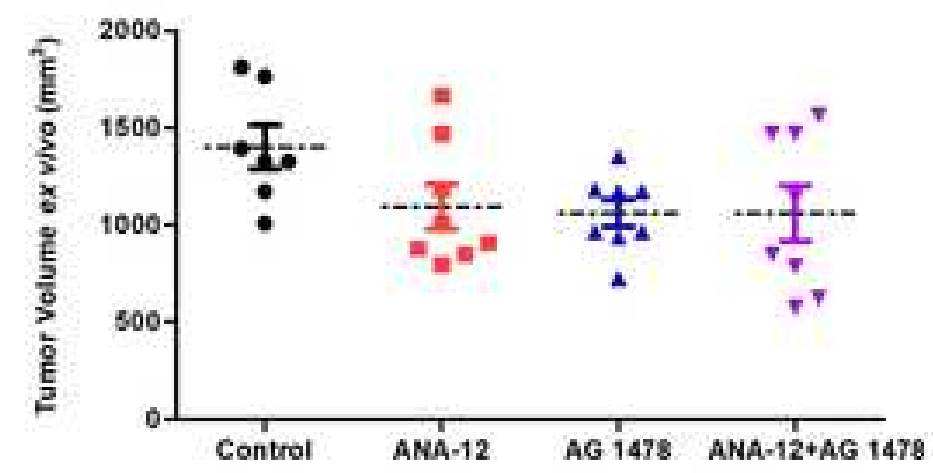

e

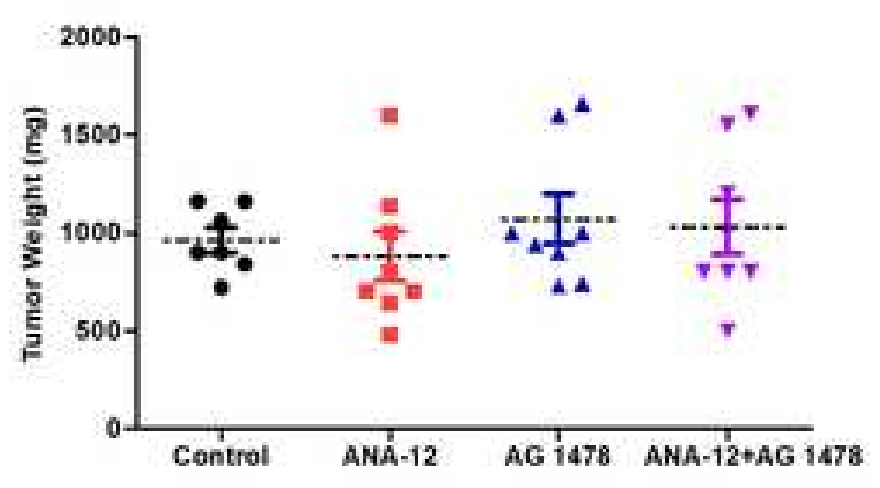

Survival

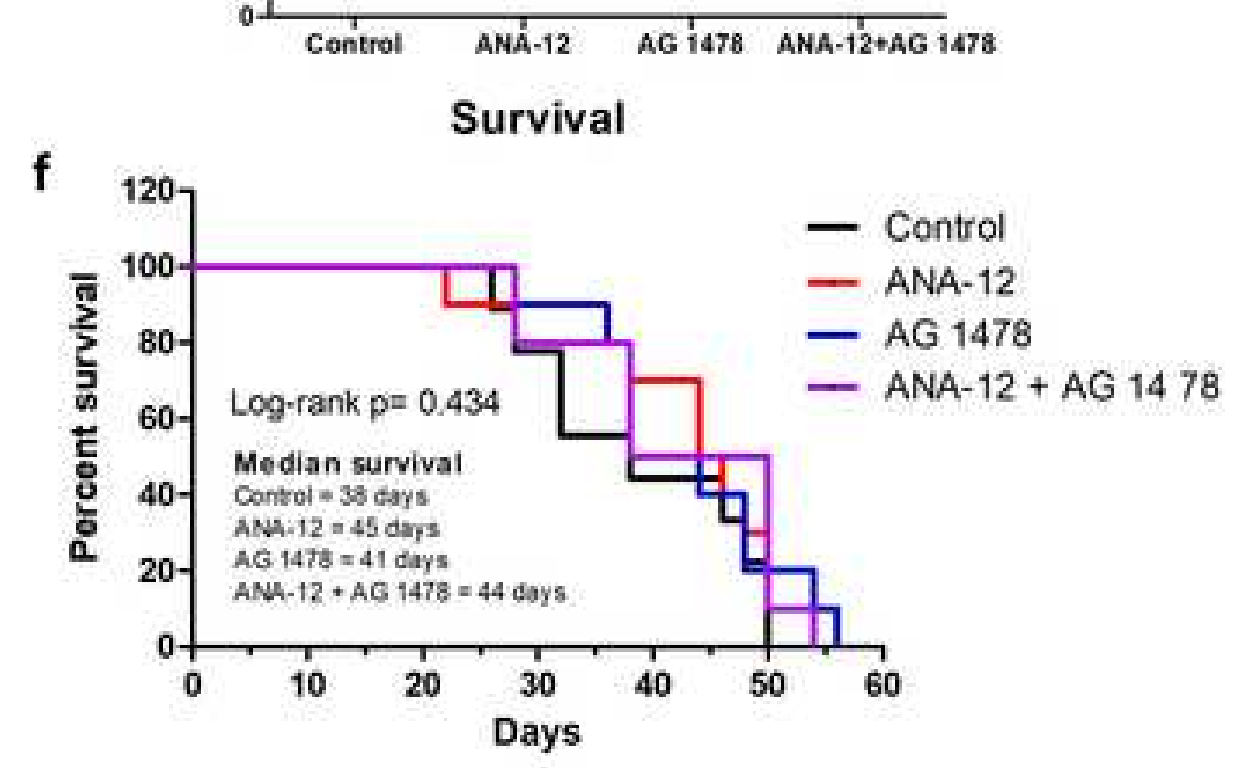


Click here to access/download Supplementary Material Supplementary information-MOLE-D-20-00758-R1.pdf 
MOLE-D-20-00758-R1

Molecular Biology Reports

ORIGINAL ARTICLE

\section{Expression and pharmacological inhibition of TrkB and EGFR in glioblastoma}

\section{Kelly de Vargas Pinheiro ${ }^{1,2} \bullet$ Amanda Thomaz ${ }^{1,2, \star} \bullet$ Bárbara Kunzler Souza ${ }^{1,2,3} \bullet$ Victoria Anne Metcalfe ${ }^{4} \bullet$ Natália Hogetop Freire ${ }^{1} \bullet$ André Tesainer Brunetto ${ }^{1,3} \bullet$ Caroline Brunetto de Farias 1,3 - Mariane Jaeger 1,3 • Victorio Bambini ${ }^{4} \bullet$ Christopher G.S. Smith ${ }^{4} \bullet$ Lisa Shaw ${ }^{4} \bullet$ Rafael Roesler ${ }^{1,2}$}

1 Cancer and Neurobiology Laboratory, Experimental Research Center, Clinical Hospital (CPE-HCPA), Federal University of Rio Grande do Sul, 90035-003 Porto Alegre, RS, Brazil

2 Department of Pharmacology, Institute for Basic Health Sciences, Federal University of Rio Grande do Sul, 90050-170 Porto Alegre, RS, Brazil

3 Children's Cancer Institute, 90620-110 Porto Alegre, RS, Brazil

4 School of Pharmacy and Biomedical Sciences, Faculty of Clinical and Biomedical Sciences, University of Central Lancashire, Preston, Lancashire, PR1 2HE, United Kingdom

Correspondence: Rafael Roesler, Department of Pharmacology, Institute for Basic Health Sciences, Federal University of Rio Grande do Sul, Rua Sarmento Leite, 500 (ICBS, Campus Centro/UFRGS), 90050-170 Porto Alegre, RS, Brazil. E-mail: rafaelroesler@ @cpa.edu.br

* Current address: Division of Biomedical and Life Sciences, Faculty of Health and Medicine, Lancaster University, Lancaster LA 4YG, United Kingdom. 


\section{Abstract}

Background: A member of the Trk family of neurotrophin receptors, tropomyosin receptor kinase B (TrkB, encoded by the NTRK2 gene) is an increasingly important target in various cancer types, including glioblastoma (GBM). EGFR is among the most frequently altered oncogenes in GBM, and EGFR inhibition has been tested as an experimental therapy. Functional interactions between EGFR and TrkB have been demonstrated. In the present study, we investigated the role of TrkB and EGFR, and their interactions, in GBM.

Methods and Results: Analyses of NTRK2 and EGFR gene expression from The Cancer Genome Atlas (TCGA) datasets showed an increase in NTRK2 expression in the proneural subtype of GBM, and a strong correlation between $N T R K 2$ and $E G F R$ expression in glioma $\mathrm{CpG}$ island methylator phenotype (G-CIMP+) samples. We showed that when TrkB and EGFR inhibitors were combined, the inhibitory effect on A172 human GBM cells was more pronounced than when either inhibitor was given alone. When U87MG GBM cells were xenografted into the flank of nude mice, tumor growth was delayed by treatment with TrkB and EGFR inhibitors, given alone or combined, only at specific time points. Intracranial GBM growth in mice was not significantly affected by drug treatments.

Conclusions: Our findings indicate that correlations between NTRK2 and EGFR expression occur in specific GBM subgroups. Also, our results using cultured cells suggest for the first time the potential of combining TrkB and EGFR inhibition for the treatment of GBM.

Keywords Brain tumor $\bullet$ Epidermal growth factor receptor $\bullet$ Glioblastoma $\bullet$ Growth factor receptor $\bullet$ Neurotrophin $\bullet$ Tropomyosin receptor kinase B 


\section{Introduction}

Growth factor receptors constitute many current and potential targets for molecularly specific therapies in cancer. The epidermal growth factor receptor (EGFR), a member of the ERBB family of transmembrane receptor tyrosine kinase (RTK) family, frequently shows gene amplification and activating mutations that contribute to driving the growth of lung and colorectal cancers [1]. EGFR is the target of clinically used small molecule inhibitors including erlotinib and gefitinib and monoclonal antibodies including cetuximab and panitumumab [2].

EGFR is among the most frequently altered oncogenes in glioblastoma (GBM), with 57\% of tumors analyzed by the The Cancer Genome Atlas Research Network (TCGA) showing amplification, mutation, rearrangement, or altered splicing [3]. GBM is the most aggressive type of primary malignant brain tumor. Current treatment based on combining surgical resection followed by radiotherapy and chemotherapy results in a median overall survival of less than 2 years $[4,5]$. To date, clinical trials with EGFR inhibitors in patients with GBM have failed to successfully improve outcomes $[6,7]$. A proposed experimental strategy to reduce resistance and improve effectiveness has been to combine EGFR inhibitors with other targeted agents acting on pathways that crosstalk with EGFR signaling [8, 9].

EGFR has been shown to functionally interact with tropomyosin receptor kinase B (TrkB, encoded by the NTRK2 gene), a member of the Trk family of neurotrophin receptors. Neurotrophins are secreted proteins importantly involved in central nervous system development, neurogenesis, and neuronal survival and plasticity [10]. Increasing evidence indicates that cancers can hijack neurotrophin signaling systems to promote tumor progression and resistance to 
treatment $[9,11]$. In colorectal cancer cells, TrkB activation by its endogenous ligand, brainderived neurotrophic factor (BDNF), promotes resistance against the EGFR inhibitor cetuximab, whereas co-treatment with TrkB and EGFR inhibitors reduce cell viability [12].

GBM tumors express BDNF and TrkB, and TrkB activation enhances the viability of brain tumor stem cells (BTSCs) from human GBMs, whereas its inhibition reduces BTSC growth [13]. TrkB blockade also hinders viability of cultured human GBM cells [14]. BDNF secreted by more differentiated GBM cells supports the growth of TrkB-expressing GBM BTSCs [15]. NTRK gene fusions are currently established as oncogenic drivers of various adult and pediatric tumor types, and larotrectinib, a first-in-class small molecule Trk inhibitor, has received approval for patients with solid tumors harboring $N T R K$ fusions [16, 17]. A gene fusion involving NTRK2 has been found to confer distinctive morphology and an aggressive phenotype in a case of low-grade glioma [18].

Here, we investigated the role of TrkB and EGFR in GBM. First, we show data on the expression of NTRK2 and correlations with EGFR expression in GBM tumors from The Cancer Genome Atlas (TGCA) datasets. We then went on to examine the effects of inhibiting EGFR and TrkB receptors, either alone or in combination, in experimental models of GBM.

\section{Materials and methods}

\section{NTRK2 and EGFR expression profiling in TCGA GBM datasets}


NTRK2 expression levels were examined in previously described The Cancer Genome Atlas (TCGA $n=631$ samples) GBM dataset and TCGA Lower Grade Glioma and Glioblastoma ( $\mathrm{n}=$ 702 samples) dataset. We used the data from gene expression array (platform: AffyU133a, version: 2017-09-08), gene expression RNAseq (platform: IlluminaHiSeq, version: 2017-09-08) and copy number (type: gene-level GISTIC2 threshold, version: 2017-09-08), data were obtained from the University of California-Santa Cruz Xena Public Data Hubs website at http://xena.ucsc.edu/. We analyzed the expression levels of NTRK2 regarding primary disease, primary tumor and recurrent samples, cytosine-phosphate-guanine $(\mathrm{CpG})$ island methylator phenotype (G-CIMP), TCGA molecular subtypes, and the correlation with EGFR expression and amplification. Additionality, we evaluated the correlation between gene expression levels of NTRK2 with patient survival outcomes.

\section{Cell culture}

Human GBM cells A172 and U87MG were obtained from American Type Culture Collection (Rockville, MD, USA) and cultured in Dulbecco's Modified Eagle's Medium (DMEM) low glucose supplemented with $10 \%$ fetal bovine serum (FBS, Gibco® by Thermo Fisher Scientific, Life Technologies, Brazil), $1 \%$ penicillin/streptomycin and $0.1 \%$ fungizone ${ }^{\circledR}(250 \mathrm{mg} / \mathrm{kg}$; Invitrogen Life Technologies, São Paulo, Brazil). Cells were maintained in a humidified atmosphere at $37^{\circ} \mathrm{C}$ and $5 \% \mathrm{CO}_{2}$. 


\section{Drug treatments}

Selective antagonists of TrkB (ANA-12) and EGFR (Tyrphostin AG 1478) were obtained from Sigma Aldrich (St. Louis, MO). ANA-12 was diluted in dimethyl sulfoxide (DMSO) in a stock solution of $6140 \mu \mathrm{M}$ and $\mathrm{AG} 1478$ was diluted in ethanol (EtOH) in a stock solution of $3167 \mu \mathrm{M}$. Other chemical reagents were obtained from qualified national and international suppliers.

\section{Cytotoxicity}

After confluence, A172 and U87MG cells were trypsinized, placed in 96- well plates at an initial density of $5.0 \times 10^{3}$ cells per well and after $24 \mathrm{~h}$ the medium was replaced by increasing concentrations of ANA-12 (0, 1, 10, 20, 30 and $50 \mu \mathrm{M})$, AG- $1478(0,1,5,10,20$ and $30 \mu \mathrm{M})$ and also combinations of both inhibitors for 24,48 or $72 \mathrm{~h}$, while the control cells were maintained in DMSO or $\mathrm{EtOH}$ when the treatments were used alone or a vehicle solution (DMSO plus EtOH) when the treatments were used in combination. In any of the situations the vehicles used did not exceed the concentration of $1 \%(\mathrm{v} / \mathrm{v})$. The effect on cell cytotoxicity was evaluated using the trypan blue exclusion method in the Neubauer chamber $[12,19]$. All assays were performed in triplicate and repeated in three independent sets.

\section{Cell cycle}

To assess cell cycle, GBM cells were cultured in 12-well plates under the same conditions as described above and after $24 \mathrm{~h}$ of exposure to treatments cells were detached, centrifuged and 
washed with PBS twice. The cells were then resuspended in $50 \mu \mathrm{g} / \mathrm{ml}$ propidium iodide (SigmaAldrich, St. Louis, Mo., USA) in $0.1 \%$ Triton X-100 in $0.1 \%$ sodium citrate solution and incubated on ice and protected from light for $15 \mathrm{~min}$. The cells were analyzed by flow cytometry (Attune® Applied Biosystems) and 20,000 events were collected per sample. Three individual experiments were performed.

\section{Ethics statement}

Experimental procedures for the subcutaneous xenograft GBM model were performed in accordance with the Brazilian Guidelines for the Care and Use of Animals in Research and Teaching [DBCA, published by National Council for the Control of Animal Experimentation (CONCEA), and approved by the institutional Animal Care Committee (Comissão de Ética no Uso de Animais CEUA, Hospital de Clínicas de Porto Alegre-HCPA), under protocol number 20160098. Animal experiments for the orthotopic xenograft GBM model were carried out under Animals (Scientific Procedures) Act, 1986 and in accordance to institutional guidelines.

\section{Animals and tumor xenografts}

Balb/c nude mice (6 to 12 weeks old) were obtained from the University Hospital Animal Research Facility (UEA, CPE-HCPA) or from Charles River Laboratories. Animals were housed four per cage and kept under aseptic conditions in ventilated cages, maintained on a $12 \mathrm{~h}$ light/dark cycle at a room temperature of $22 \pm 2{ }^{\circ} \mathrm{C}$. They were allowed ad libitum access to standardized pellet food and water. For the ex-vivo pharmacological inhibition, U87MG cells were cultured in $75 \mathrm{~cm}^{2}$ 
or $175 \mathrm{~cm}^{2}$ culture flasks and treated with $13.85 \mu \mathrm{M}$ of ANA-12, $13.26 \mu \mathrm{M}$ of AG 1478 (alone or in combination) or vehicle (DMSO plus EtOH) for $24 \mathrm{~h}$. A total of $1 \times 10^{6}$ viable cells were processed in serum-free DMEM and diluted 1:1 with Matrigel (Corning, Corning, USA) and then injected subcutaneously (s.c) into the right flank of nude mice (6-8 mice per group). Measurements started five days after cells inoculation, when tumors reached approximately $40-75 \mathrm{~mm}^{3}$. The dimensions, length (L) and width (W), of the resulting tumors were determined every two days using a manual caliper, and the tumor volume $\left(\mathrm{mm}^{3}\right)$ was calculated using the formula: tumor volume $=\left[\right.$ length ${ }^{2} \mathrm{x}$ width/2]. When tumors reached the endpoint $\left(800-1000 \mathrm{~mm}^{3}\right)$ mice were euthanized, and the tumors were excised, measured, and weighed.

For the orthotopic xenograft model, mice were anesthetized with isoflurane (4\% oxygen) and placed in a stereotactic platform. The tops of the heads were disinfected, and a small incision was made in the scalp over the midline. A burr hole was made in the skull to a position $2 \mathrm{~mm}$ posterior and $1.5 \mathrm{~mm}$ lateral to the bregma in the right cerebral hemisphere. Next, mice were injected with 40,000 U87MG cells processed in serum-free DMEM in a volume of $2 \mu \mathrm{l}$ using an injector syringe pump. The burr hole in the skull was closed with sterile bone wax and veterinary tissue glue was used to seal the incision. After surgery, the mice were placed in a recovery cage set to $37^{\circ} \mathrm{C}$ until the animal recovered consciousness. Mice were monitored daily for signs of sickness, pain or weight loss. Seven days followed the surgery the animals were randomized into 4 groups ( $n=5$ per group) to receive intraperitoneal (i.p.) injections for 21 days, and were treated by a blinded investigator with ANA-12 (1 mg/kg/daily plus vehicle for AG1478 every 3 days), AG1478 (10 $\mathrm{mg} / \mathrm{kg}$ every three days plus vehicle for ANA-12 daily), ANA-12 (1 mg/kg daily) plus AG 1478 (10 mg/kg every three days). Control animals received ANA-12 and vehicle (DMSO 2\% in saline

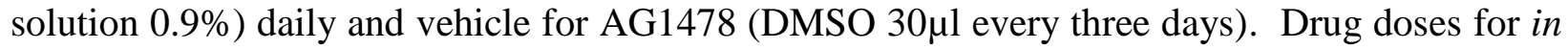


vivo experiments were chosen on the basis of previous studies [20 - 24]. Both drugs readily enter the brain when given systemically in mice or rats $[21,25]$.

\section{Fluorescence imaging}

Administration of 5-aminolevulinic acid (5-ALA), that leads to the synthesis and accumulation of fluorescent protoporphyrin IX (PPIX), has been used with fluorescence-guided surgery to directly visualize high-grade gliomas. After 21 days of treatment, the animals received an i.p. injection of 5-ALA; $50 \mathrm{mg} / \mathrm{kg}$ and after 1 hour the mice were euthanized by cervical dislocation and the brains were removed to be analyzed. The IVIS system was used to record the ex-vivo fluorescent signal from tumors. First, we imaged the whole brains and next we used a brain matrix to cut sequential $1 \mathrm{~mm}$ slices, in order to improve fluorescence detection, and the slices were also imaged. Data acquisition and analysis was performed with Living Image software (Caliper LS living image version: 4.5.2.18424-september 11 2015, camera: IS1621N6980, Andor, iKon). In radiant efficiency mode, the wavelengths for emission and excitation were 620 and 420 respectively, and fixed size of regions of interest (ROIs) were drawn covering the whole tumor. The fluorescent signals (total radiant efficiency/sec) were quantitated by subtracting background fluorescence from tumor signal.

\section{Statistical analysis}

Statistical analysis of gene expression in two or more groups from the TCGA transcriptome datasets were performed using Welch's t-test and Kruskal-Wallis test for significance and Dunn's 
tests for post hoc comparisons, respectively. Correlation analysis were performed by the Pearson correlation method. Survival distribution was estimated according to the Kaplan-Meier method using a median cut-off and log-rank statistics. These analyses were executed using the Graphpad 8.0 software. Significant differences were revealed by $p$ values below 0.05 .

Experimental data were expressed as mean \pm SEM. In vitro and in vivo experiments were analyzed using the GraphPad Prism software package, v. 5.0 (GraphPad, San Diego, CA). The level of significance between different experimental groups was performed using analysis of variance (ANOVA) followed by appropriate post-hoc tests; $p<0.05$ was considered statistically significant. A drug combination analysis was performed based on the $50 \%$ inhibitory concentration (IC50) of the treatments. For calculation of IC50 data were fitted in a dose response curve (Graphpad Prism v. 5.0) using the equation $\mathrm{Y}=100 /\left(1+10^{\wedge}((\mathrm{X}-\log \mathrm{IC} 50))\right)$. The interaction between ANA-12 and AG-1478 was assessed by the combination index method (Cl) [26]. Synergism, addition and antagonism between drug combinations were defined as $\mathrm{CI}<0.9, \mathrm{CI}=$ 0.9-1.1 and CI > 1.1, respectively.

\section{Results}

\section{NTRK2 expression levels are increased in lower grade glioma, proneural GBM subtype and GBM methylated phenotype in GBM patients}

We evaluated TCGA GBM datasets to explore whether NTRK2 expression correlates with EGFR expression, GBM subtype and patient survival. First, we classified TCGA samples by primary disease type between lower grade glioma (LGG) and GBM, based on array data available for 702 
samples. NTRK2 expression was increased in LGG in comparison to GBM samples (Fig. 1A, $p<$ 0.0001). We also evaluated the levels of NTRK2 across normal brain samples, primary and recurrent tumors, however, no statistical differences were observed between these groups (Fig. 1B, $p=0.220$ ). Based on the definition of GBM molecular subtypes, we found that NTRK2 expression was lower in the mesenchymal subtype when compared with neural and proneural subtypes (Fig. 1C, $p<0.01)$. NTRK2 expression was highest in the proneural group in comparison with classical and mesenchymal subtypes (Fig. 1C, $p<0.0001$ ). Given that the proneural group is associated with $I D H$ mutations and $I D H$-mutant gliomas manifest the cytosine-phosphate-guanine (CpG) island methylator phenotype (G-CIMP), we evaluated the expression of NTRK2 regarding the methylation phenotype between G-CIMP ${ }^{+}$and G-CIMP-. We observed an increased expression of NTRK2 in G-CIMP ${ }^{+}$samples (Fig. 1D, $p<0.01$ ), which is consistent with the increased expression in the proneural subtype.

\section{Correlations between NTRK2 and EGFR expression in GBM tumors}

To analyze whether the NTRK2 expression correlates with EGFR levels, we performed correlation analysis across samples registered with TCGA dataset. We detected a weak correlation between NTRK2 and EGFR expression when considering all GBM samples together (Fig. 1E, correlation $=0.1603, p=0.0002$ ) and G-CIMP GBM samples (Fig. $1 \mathrm{G}$, correlation $=0.1869, p=0.0001$ ). A moderate correlation between NTRK2 and EGFR expression was found in G-CIMP+ samples (Fig. $1 \mathrm{~F}$, correlation $=0.3443, p=0.0221)$.

We also determined the relationship between NTRK2 expression and patient overall survival (Fig. 1H), using median of NTRK2 expression as a cutoff between low and high 
expression. We further looked at the effect of NTRK2 expression in patients stratified by EGFR amplification (Fig. 1I). Survival of GBM patients was not significantly different when tumors with high and low NTRK2 expression levels were compared.

Figure 1 should be inserted here

\section{Selective inhibition of TrkB and EGFR decreases GBM cell viability}

To examine the effects of TrkB and EGFR inhibition on cell viability, GBM cells were treated with ANA-12 and AG 1478 alone or in combination and viability was assessed by the trypan blue exclusion method. Time course analysis showed that both single treatments decreased A172 and U87MG cell viability when compared with control cells treated with vehicle $(p<0.001)$. The effect was observed in A172 cells after 48 hours of treatment with ANA-12 at $10 \mu \mathrm{M}$ or AG1478 at $30 \mu \mathrm{M}$ (Fig. 2A, 2B). A similar effect was observed in U87MG cells after 24 hours of treatment with the dose of $10 \mu \mathrm{M}$ of ANA-12 or AG1478 (Fig. 2C, 2D). We also analyzed whether the reduction of cell viability with ANA-12 or AG1478 were dose-dependent. As depicted in Fig. 2, both treatments showed features of dose-dependent effect in A172 and U87MG cells. After time course and dose-response curves analysis, we defined proper doses and time to evaluate the effect of the combination (ANA-12 plus AG1478) on cell viability. When the two drugs were combined the inhibitory effect was more pronounced in A172 cells compared to either IC50-equivalent 
isolated drugs and in the combination of both drugs in higher doses (see Fig. 2I for detailed results and $p$ values for specific comparisons). In contrast, the effect of the combination treatment was not more pronounced than those of each single treatment at equivalent doses in U87MG cells (Fig.2J).

Figure 2 should be inserted here

\section{Pharmacological interactions between TrkB and EGFR inhibitors}

In order to evaluate drug interaction effects, IC50-values were calculated from the effects seen in the cytotoxicity assay (Fig. 3). ANA-12 had IC50 values of 10.0 (7-14) $\mu \mathrm{M}$ and 13.85 (11-17) $\mu \mathrm{M}$ for A172 and U87MG cells, respectively. IC50 values of AG1478 were 20.0 (16-21) $\mu \mathrm{M}$ for A172 cells and 13.26 (11-16) $\mu \mathrm{M}$ for U87MG cells (Fig. 3A). Pharmacological interactions of the combined treatment with ANA-12 and AG1478 were investigated using cytotoxicity as the chosen outcome and evaluated by Chou-Talalay method (Chou and Talalay 1984). Synergism, addition and antagonism for drug combinations was defined as $\mathrm{CI}<0.9, \mathrm{CI}=0.9-1.1$ and $\mathrm{CI}>1.1$, respectively. We observed synergy in A172 cells $(\mathrm{CI}=0.75)$. However, in U87MG cells the inhibitors presented antagonism, as shown by the combination index value of 2.2 (Fig. 3B). 


\section{Figure 3 should be inserted here}

\section{TrkB and EGFR inhibitors induce changes in cell cycle features of GBM cells}

Effects on cell cycle were evaluated by flow cytometry after treatment with ANA-12 and AG 1478 alone or in combination in GBM cells. As shown in Fig. 4, the TrkB inhibitor induced a significant reduction in S phase, which starts at the dose of $10 \mu \mathrm{M}$ and persists at a dose of $20 \mu \mathrm{M}$ in A172 cells (Fig. 4A $p<0.001$ and $p<0.0001$, respectively). An increase in cells in the S phase after TrkB inhibition was observed in U87MG cells at the dose of $50 \mu \mathrm{M}(p<0.05$, Fig. 4D). Treatment with $30 \mu \mathrm{M}$ of AG 1478 significantly increased the number of A172 and U87MG cells in G0/G1 phase when compared with control cells (Fig. 4B, 4E, $p<0.01$ and $p<0.05$, respectively). The combined treatment lead to a combination of effects leading to both accumulation of cells in G0/G1 and reduction of S phase in A172 cells (Fig. 4C $p<0.05$ and $p<0.01$ ). The combined treatment did not cause significant changes in the cell cycle of U87MG cells; however, we could observe a small percentage of cells in Sub-G1 phase when compared with controls (Fig. 4F, $p<0.05$ ).

Figure 4 should be inserted here 


\section{Long-term effects of TrkB and EGFR inhibition in a GBM xenograft mouse model}

To explore the roles of EGFR and TrkB during tumorigenesis, we used a preclinical subcutaneous xenograft GBM model. U87MG cells were treated with ANA-12, AG 1478, ANA-12 plus AG 1478 and DMSO or EtOH. After $24 \mathrm{~h}$, the animals were randomized and viable pre-treated U87MG cells were injected subcutaneously into the right flank of mice (Fig. 5A). Fig. 5B illustrates tumor volume size across different days. Tumor size was significantly different in day 15 in all treatment groups when compared with controls given vehicle. Mice that received cells treated with ANA12, alone or combined with AG 1478, also showed smaller tumors at day 31. The apparent reduction in tumor size in all drug-treated groups compared to controls at day 45 did not reach statistical significance (Fig. 5C). When tumors reached $800-100 \mathrm{~mm}^{3}$ the mice were euthanized, and the tumors were excised, and weight and volume were determined. Ex-vivo tumor analysis showed an apparent reduction in tumor volume when compared treatment groups with control, however, these differences did not reach statistical significance (Fig. 5D). Moreover, there were no statistically significant differences among groups regarding tumor weight (Fig. 5E). We also evaluated possible differences in survival comparing treatment groups with control group. Although the median survival days of the control group (38 days) was lower when compared to treatment groups (ANA-12, 45 days; AG 1478, 41 days; ANA-12+AG 1478, 44 days), no statistically differences were observed (Fig. 5F). 
Figure 5 should be inserted here

\section{Lack of effect of combined TrkB and EGFR inhibition on intracranial GBM tumor growth}

We tested the hypothesis that the combined inhibition of TrkB plus EGFR would inhibit the growth of intracranial GBM in mice. Seven days after inoculation of U87MG cells, mice were randomized to receive i.p. injections in a period of 21 days with ANA-12 $(1 \mathrm{mg} / \mathrm{kg}$ daily plus vehicle every 3 days), AG1478 (10 mg/kg every three days plus vehicle daily), ANA-12 (1 mg/kg daily) plus AG $1478(10 \mathrm{mg} / \mathrm{kg}$ every three days) and vehicle daily. During the treatment period, mice were monitored daily for any signs of sickness, pain or weight loss. The tumor growth was analyzed by ex-vivo brain fluorescent imaging of the different groups using the IVIS system after 29 days after cell inoculation. Tumor fluorescence did not reveal a significant difference among groups $(p=$ 0.771; Suppl. Fig. S1).

\section{Discussion}

Gene expression analysis in GBM tumor datasets showed an increased NTRK2 expression in proneural, G-CIMP ${ }^{+}$GBMs. Interestingly, significant correlations between NTRK2 and EGFR 
expression levels were found in GBM, particularly in G-CIMP+ tumors. Previous analyses of TCGA GBMs have shown that G-CIMP+ glioblastomas presented reduced mRNA levels for EGFR due to epigenetic regulation [27]. The proneural G-CIMP phenotype confers a survival advantage for GBM patients [3], and its possible relationship with NTRK2 expression revealed here warrants further exploration.

One of the main findings in the present study was that the combined inhibition of TrkB and EGFR was more pronounced than either treatment given alone in impairing A172 GBM cell viability. This result is consistent with the view that TrkB inhibition may sensitize cancer cells to the effects of EGFR inhibitors [28]. ANA-12, originally developed as an experimental antidepressant, selectively and efficiently inhibits TrkB by binding to both low- and high-affinity sites on the receptor extracellular domain [21]. AG 1478 is a selective EGFR inhibitor that shares a structural quinazoline main chain with the clinically used EGFR inhibitors gefitinib and erlotinib [20]. The results observed with these two small-molecule compounds in two different mouse GBM xenograft models were less clear. When cells were pretreated with drug treatments before being xenografted into the flanks of nude mice, treatments were able to slow tumor growth only at specific time points (15 and 31 days after cell inoculation), but drug-treated tumors were able to reach sizes comparable to controls by the end of the follow-up period. In addition, treatments did not significantly change tumor progression assessed by fluorescence in mice receiving GBM cells intracranially followed by systemic drug treatments. Given the potency of ANA-12 and AG1478 inhibition of cell viability in vitro, we expected to observe pronounced drug effects in in vivo models. A possible limitation was measuring fluorescence only at the end of treatment rather than at different time points during treatment. Importantly, EGFR may have a dual role, contributing to tumor progression but also conferring increased DNA damage response and high sensitivity to the 
inhibitor talazoparib [29]. Thus, differential roles of EGFR signaling could occur under the different experimental conditions we used (for example, regulation by the tumor microenvironment in in vivo assays), resulting in contrasting findings. The lack of effects may also be related to the choice of drug doses in our experiments. The drug doses and treatment regimens we used for in vivo experiments were based on previous studies that used xenograft models of GBM and other cancer types [22, 24, 25]. It is still possible that, as suggested by our results shown in Fig. 3, the two drugs used show antagonistic activity in U87MG cells. Another point worth mentioning is that, together, the results obtained in our in vitro and flank xenograft experiments might suggest that TrkB and EGFR inhibition can delay GBM growth in the short-term, but not after longer delays, when tumors are able to recover full growth.

One issue worthy discussing is the opposite pattern of effects on cytotoxity between the two cell lines. Pharmacological interaction analysis showed synergism in A172 cells but antagonism in U87 MG cells. In terms of genetic profiles, both A172 and U87 MG cells are mutant for both CDKN2A and PTEN. However, U87 MG cells express only wild-type EGFR, whereas A172 cells also express TDM/18-26 mutant EGFR [30, 31]. This biological difference might be crucial to explain the contrasting effects we observed between cell lines. In addition, we have previously observed, in experiments using medulloblastoma cells, that BDNF/TrkB signaling may have opposite effects on cell viability, so TrkB activation can either induce or prevent cytotoxicity depending on drug combinations and experimental conditions [32 - 34]. In fact, BDNF can play opposite actions depending on changes in cellular context. These differential effects may involve distinct isoforms of TrkB expressed in different cell tumor types [34]. This dependency on cellular environment might also be related to the switch from synergism to antagonism we observed when TrkB inhibition was combined with EGFR inhibitor. GBM tumors interact in complex ways with 
a microenvironment consisting of glial, endothelial, and immune cells. Several signaling molecules, including growth factors, mediate intercellular communication between GBM cells and cells composing the microenvironment [35 - 37]. It is thus possible that the interactions between receptors such as TrkB and EGFR in GBM, as well as the effects of receptor inhibitors, are modulated by biochemical signals from the microenvironment. It is also possible that inhibitors interact directly with receptors on cells in the microenvironment, resulting in changes of drug responses in vivo compared to in vitro models. These are complex issues that warrant further research in the field of targeted therapies for GBM.

GBM differentiated cells have been shown to secrete BDNF to stimulate TrkB in GBM stem cells and induce them to secrete nerve growth factor inducible (VGF), a neuropeptide that promotes survival and growth of GBM stem-like and differentiated cells [15]. TrkB knockdown or pharmacological inhibition of TrkB hinders BDNF-dependent GBM stem-like cell growth [13]. TrkB-containing exosomes promote the transfer of aggressiveness between GBM cells [38]. EGFR inhibition has been proposed as a therapeutic strategy in GBM and has been tested in preclinical [39 - 41] and clinical [42, 43] studies, with mixed results. One previous study examined the interaction between TrkB and EGFR in experimental GBM and showed that stimulation of neurotrophin signaling can overcome the inhibitory effects of EGFR inhibition on GBM cell growth [13]. The present study is the first one to verify whether the combined inhibition of TrkB and EGFR may effectively reduce GBM growth.

In summary, analysis of TCGA tumors showed that correlations between NTRK2 and EGFR expression can be observed in GBM, and the role of TrkB and EGFR in the proneural, G$\mathrm{CIMP}^{+}$subtype of GBM should be further investigated by future studies. In addition, our results 
using cultured cells indicate for the first time the potential of combining TrkB and EGFR inhibition for the treatment of GBM, however we could not observe pronounced effects in vivo.

Acknowledgements This article has been previously published as a preprint at https://www.biorxiv.org/content/10.1101/2020.02.03.932608v1.

Funding This research was supported by the National Council for Scientific and Technological Development (CNPq; grant numbers 409287/2016-4 and 305647/2019-9 to R.R.); the Coordination for the Improvement of Higher Education Personnel (CAPES); the Children's Cancer Institute (ICI); the Clinical Hospital institutional research fund (FIPE/HCPA); the University of Central Lancashire; InbetweenEars; and the Brain Tumour North West Research Consortium.

Disclosure of potential conflicts of interest The authors declare that they have no competing interests related to the contents of this manuscript.

Research involving human participants and/or animals Not applicable.

Informed consent Not applicable. 


\section{References}

1. Mitsudomi T, Yatabe Y (2010) Epidermal growth factor receptor in relation to tumor development: EGFR gene and cancer. FEBS J 277(2): 301-308

2. Arteaga CL, Engelman JA (2014) ERBB receptors: from oncogene discovery to basic science to mechanism-based cancer therapeutics. Cancer Cell 25(3): 282-303

3. Brennan CW, Verhaak RG, McKenna A, Campos B, Noushmehr H, Salama SR, Zheng S, Chakravarty D, Sanborn JZ, Berman SH, Beroukhim R, Bernard B, Wu CJ, Genovese G, Shmulevich I, Barnholtz-Sloan J, Zou L, Vegesna R, Shukla SA, Ciriello G, Yung WK, Zhang W, Sougnez C, Mikkelsen T, Aldape K, Bigner DD, Van Meir EG, Prados M, Sloan A, Black KL, Eschbacher J, Finocchiaro G, Friedman W, Andrews DW, Guha A, Iacocca M, O'Neill BP, Foltz G, Myers J, Weisenberger DJ, Penny R, Kucherlapati R, Perou CM, Hayes DN, Gibbs R, Marra M, Mills GB, Lander E, Spellman P, Wilson R, Sander C, Weinstein J, Meyerson M, Gabriel S, Laird PW, Haussler D, Getz G, Chin L; TCGA Research Network (2013) The somatic genomic landscape of glioblastoma. Cell 155(2): $462-477$

4. Stupp R, Mason WP, van den Bent MJ, Weller M, Fisher B, Taphoorn MJ, Belanger K, Brandes AA, Marosi C, Bogdahn U, Curschmann J, Janzer RC, Ludwin SK, Gorlia T, Allgeier A, Lacombe D, Cairncross JG, Eisenhauer E, Mirimanoff RO; European Organisation for Research and Treatment of Cancer Brain Tumor and Radiotherapy Groups; National Cancer Institute of Canada Clinical Trials Group (2005) Radiotherapy 
plus concomitant and adjuvant temozolomide for glioblastoma. N Engl J Med 352(10): 987-996

5. Wen PY, Kesari S (2008) Malignant gliomas in adults. N Engl J Med 359(5): 492-507

6. van den Bent MJ, Brandes AA, Rampling R, Kouwenhoven MC, Kros JM, Carpentier AF, Clement PM, Frenay M, Campone M, Baurain JF, Armand JP, Taphoorn MJ, Tosoni A, Kletzl H, Klughammer B, Lacombe D, Gorlia T (2009) Randomized phase II trial of erlotinib versus temozolomide or carmustine in recurrent glioblastoma: EORTC brain tumor group study 26034. J Clin Oncol 27(8): 1268-1274

7. Vivanco I, Robins HI, Rohle D, Campos C, Grommes C, Nghiemphu PL, Kubek S, Oldrini B, Chheda MG, Yannuzzi N, Tao H, Zhu S, Iwanami A, Kuga D, Dang J, Pedraza A, Brennan CW, Heguy A, Liau LM, Lieberman F, Yung WK, Gilbert MR, Reardon DA, Drappatz J, Wen PY, Lamborn KR, Chang SM, Prados MD, Fine HA, Horvath S, Wu N, Lassman AB, DeAngelis LM, Yong WH, Kuhn JG, Mischel PS, Mehta MP, Cloughesy TF, Mellinghoff IK (2012) Differential sensitivity of glioma- versus lung cancer-specific EGFR mutations to EGFR kinase inhibitors. Cancer Discov 2(5): 458-471

8. Keller S, Schmidt MHH (2017) EGFR and EGFRvIII promote angiogenesis and cell invasion in glioblastoma: Combination therapies for an effective treatment. Int J Mol Sci 18(6): E129

9. Roesler R, Brunetto AT, Abujamra AL, de Farias CB, Brunetto AL, Schwartsmann G (2010) Current and emerging molecular targets in glioma. Expert Rev Anticancer Ther 10(11): 1735-1751 
10. Park H., Poo MM (2013) Neurotrophin regulation of neural circuit development and function. Nat Rev Neurosci 14(1): 7-23

11. Thiele CJ, Li Z, McKee AE (2009) On Trk--the TrkB signal transduction pathway is an increasingly important target in cancer biology. Clin Cancer Res 15(19): 5962-5967

12. de Farias CB, Heinen TE, dos Santos RP, Abujamra AL, Schwartsmann G, Roesler R (2012) BDNF/TrkB signaling protects HT-29 human colon cancer cells from EGFR inhibition. Biochem Biophys Res Commun 425(2): 328-332

13. Lawn S, Krishna N, Pisklakova A, Qu X, Fenstermacher DA, Fournier M, Vrionis FD, Tran N, Chan JA, Kenchappa RS, Forsyth PA (2015) Neurotrophin signaling via TrkB and TrkC receptors promotes the growth of brain tumor-initiating cells. J Biol Chem 290(6): 3814-3824

14. Pinheiro KV, Alves C, Buendia M, Gil MS, Thomaz A, Schwartsmann G, de Farias CB, Roesler R (2017) Targeting tyrosine receptor kinase B in gliomas. Neuro Oncol 19(1): 138139

15. Wang X, Prager BC, Wu Q, Kim LJY, Gimple RC, Shi Y, Yang K, Morton AR, Zhou W, Zhu Z, Obara EAA, Miller TE, Song A, Lai S, Hubert CG, Jin X, Huang Z, Fang X, Dixit D, Tao W, Zhai K, Chen C, Dong Z, Zhang G, Dombrowski SM, Hamerlik P, Mack SC, Bao S, Rich JN (2018) Reciprocal signaling between glioblastoma stem cells and differentiated tumor cells promotes malignant progression. Cell Stem Cell 22(4): 514528.e5

16. Cocco E, Scaltriti M, Drilon A (2018) NTRK fusion-positive cancers and TRK inhibitor therapy. Nat Rev Clin Oncol 15(12): 731-747 
17. Drilon A, Laetsch TW, Kummar S, DuBois SG, Lassen UN, Demetri GD, Nathenson M, Doebele RC, Farago AF, Pappo AS, Turpin B, Dowlati A, Brose MS, Mascarenhas L, Federman N, Berlin J, El-Deiry WS, Baik C, Deeken J, Boni V, Nagasubramanian R, Taylor M, Rudzinski ER, Meric-Bernstam F, Sohal DPS, Ma PC, Raez LE, Hechtman JF, Benayed R, Ladanyi M, Tuch BB, Ebata K, Cruickshank S, Ku NC, Cox MC, Hawkins DS, Hong DS, Hyman DM (2018) Efficacy of larotrectinib in TRK fusion-positive cancers in adults and children. $\mathrm{N}$ Engl J Med 378(8): 731-739

18. Jones KA, Bossler AD, Bellizzi AM, Snow AN (2019) BCR-NTRK2 fusion in a low-grade glioma with distinctive morphology and unexpected aggressive behavior. Cold Spring Harb Mol Case Stud 5(2). pii: a003855

19. Thomaz A, Jaeger M, Buendia M, Bambini-Junior V, Gregianin LJ, Brunetto AL, Brunetto AT, de Farias CB, Roesler R (2016) BDNF/TrkB signaling as a potential novel target in pediatric brain tumors: Anticancer activity of selective TrkB inhibition in medulloblastoma cells. J Mol Neurosci 59(3): 326-333

20. Ellis AG, Doherty MM, Walker F, Weinstock J, Nerrie M, Vitali A, Murphy R, Johns TG, Scott AM, Levitzki A, McLachlan G, Webster LK, Burgess AW, Nice EC (2006) Preclinical analysis of the analinoquinazoline AG1478, a specific small molecule inhibitor of EGF receptor tyrosine kinase. Biochem Pharmacol 71(10): 1422-1434

21. Cazorla M, Prémont J, Mann A, Girard N, Kellendonk C, Rognan D (2011) Identification of a low-molecular weight TrkB antagonist with anxiolytic and antidepressant activity in mice. J Clin Invest 121(5): 1846-1857 
22. Yu Y, Zhang M, Zhang X, Cai Q, Hong S, Jiang W, Xu C (2014) Synergistic effects of combined platelet-activating factor receptor and epidermal growth factor receptor targeting in ovarian cancer cells. J Hematol Oncol 7: 39

23. Li W, Fang Q, Zhong P, Chen L, Wang L, Zhang Y, Wang J, Li X, Wang Y, Wang J, Liang G (2016) EGFR inhibition blocks palmitic acid-induced inflammation in cardiomyocytes and prevents hyperlipidemia-induced cardiac injury in mice. Sci Rep 6: 24580

24. Thomaz A, Pinheiro KV, Souza BK, Gregianin L, Brunetto AL, Brunetto AT, de Farias CB, Jaeger MDC, Ramaswamy V, Nör C, Taylor MD, Roesler R (2019) Antitumor activities and cellular changes induced by TrkB inhibition in medulloblastoma. Front Pharmacol 10: 698

25. Nagane M, Narita Y, Mishima K, Levitzki A, Burgess AW, Cavenee WK, Huang HJ (2001) Human glioblastoma xenografts overexpressing a tumor-specific mutant epidermal growth factor receptor sensitized to cisplatin by the AG1478 tyrosine kinase inhibitor. J Neurosurg 95: 472-479

26. Chou TC, Talalay P (1984) Quantitative analysis of dose-effect relationships: the combined effects of multiple drugs or enzyme inhibitors. Adv Enzyme Regul 22: 27-55.

27. Li J, Taich ZJ, Goyal A, Gonda D, Akers J, Adhikari B, Patel K, Vandenberg S, Yan W, Bao Z, Carter BS, Wang R, Mao Y, Jiang T, Chen CC (2014) Epigenetic suppression of EGFR signaling in G-CIMP+ glioblastomas. Oncotarget 5(17): 7342-7356

28. Roesler R, de Farias CB, Abujamra AL, Brunetto AL, Schwartsmann G (2011) BDNF/TrkB signaling as an anti-tumor target. Expert Rev Anticancer Ther 11(10): 14731475 
29. Wu S, Gao F, Zheng S, Zhang C, Martinez-Ledesma E, Ezhilarasan R, Ding J, Li X, Feng N, Multani A, Sulman EP, Verhaak RG, de Groot JF, Heffernan TP, Yung WKA, Koul D (2020) EGFR amplification induces increased DNA damage response and renders selective sensitivity to Talazoparib (PARP inhibitor) in glioblastoma. Clin Cancer Res 26(6): 13951407

30. Ciesielski MJ, Fenstermaker RA (2000) Oncogenic epidermal growth factor receptor mutants with tandem duplication: gene structure and effects on receptor function. Oncogene 19(6): 810-820

31. Carrasco-García E, Saceda M, Grasso S, Rocamora-Reverte L, Conde M, Gómez-Martínez A, García-Morales P, Ferragut JA, Martínez-Lacaci I (2011) Small tyrosine kinase inhibitors interrupt EGFR signaling by interacting with erbB3 and erbB4 in glioblastoma cell lines. Exp Cell Res 317(10): 1476-1489

32. Schmidt AL, de Farias CB, Abujamra AL, Kapczinski F, Schwartsmann G, Brunetto AL, Roesler R (2010) BDNF and PDE4, but not the GRPR, regulate viability of human medulloblastoma cells. J Mol Neurosci 40: 303-310

33. Nör C, de Farias CB, Abujamra AL, Schwartsmann G, Brunetto AL, Roesler R (2011) The histone deacetylase inhibitor sodium butyrate in combination with brain-derived neurotrophic factor reduces the viability of DAOY human medulloblastoma cells. Childs Nerv Syst 27: 897-901

34. Radin DP, Patel P (2017) BDNF: an oncogene or tumor suppressor? Anticancer Res 37(8): 3983-3990 
35. de Almeida Sassi F, Lunardi Brunetto A, Schwartsmann G, Roesler R, Abujamra AL (2012) Glioma revisited: from neurogenesis and cancer stem cells to the epigenetic regulation of the niche. J Oncol 2012: 537861

36. Perus LJM, Walsh LA (2019) Microenvironmental heterogeneity in brain malignancies. Front Immunol 10: 2294

37. Simon T, Jackson E, Giamas G (2020) Breaking through the glioblastoma microenvironment via extracellular vesicles. Oncogene 39: 4477-4490

38. Pinet S, Bessette B, Vedrenne N, Lacroix A, Richard L, Jauberteau MO, Battu S, Lalloué F (2016) TrkB-containing exosomes promote the transfer of glioblastoma aggressiveness to YKL-40-inactivated glioblastoma cells. Oncotarget 7(31): 50349-50364

39. Parker JJ, Dionne KR, Massarwa R, Klaassen M, Foreman NK, Niswander L, Canoll P, Kleinschmidt-Demasters BK, Waziri A (2013) Gefitinib selectively inhibits tumor cell migration in EGFR-amplified human glioblastoma. Neuro Oncol 15(8): 1048-1057

40. Zahonero C, Aguilera P, Ramírez-Castillejo C, Pajares M, Bolós MV, Cantero D, PerezNuñez A, Hernández-Laín A, Sánchez-Gómez P, Sepúlveda JM (2015) Preclinical test of dacomitinib, an irreversible EGFR inhibitor, confirms its effectiveness for glioblastoma. Mol Cancer Ther 14(7): 1548-1558

41. Buendia Duque M, Pinheiro KV, Thomaz A, da Silva CA, Freire NH, Brunetto AT, Schwartsmann G, Jaeger M, de Farias CB, Roesler R (2019) Combined inhibition of HDAC and EGFR reduces viability and proliferation and enhances STAT3 mRNA expression in glioblastoma cells. J Mol Neurosci 68(1): 49-57 
42. Sepúlveda-Sánchez JM, Vaz MÁ, Balañá C, Gil-Gil M, Reynés G, Gallego Ó, MartínezGarcía M, Vicente E, Quindós M, Luque R, Ramos A, Ruano Y, Pérez-Segura P, Benavides M, Sánchez-Gómez P, Hernández-Laín A (2017) Phase II trial of dacomitinib, a pan-human EGFR tyrosine kinase inhibitor, in recurrent glioblastoma patients with EGFR amplification. Neuro Oncol 19(11): 1522-1531

43. Makhlin I, Salinas RD, Zhang D, Jacob F, Ming GL, Song H, Saxena D, Dorsey JF, Nasrallah MP, Morrissette JJ, Binder ZA, O'Rourke DM, Desai AS, Brem S, Bagley SJ (2019) Clinical activity of the EGFR tyrosine kinase inhibitor osimertinib in EGFR-mutant glioblastoma. CNS Oncol 8(3): CNS43 


\section{Legends for figures}

Fig 1 NTRK2 expression and its correlation with EGFR expression levels in TCGA GBM datasets. Transcript levels of NTRK2 were examined in previously described transcriptome datasets from the TCGA GBM dataset ( $n=631$ samples) and the TCGA Lower Grade Glioma (LGG) and GBM ( $n=702$ samples) dataset. (A) Expression levels of NTRK2 in LGG and GBM patient cohorts. (B) Normal brain, primary and recurrent GBM samples. (C) GBM subtypes. (D) cytosine-phosphateguanine $(\mathrm{CpG})$ island methylator phenotype (G-CIMP). Data was presented in violin plot format as log2-transformed signal intensity and statistical analyses were performed using Kruskal-Wallis test followed by Dunn's post hoc tests, ${ }^{*} p<0.05 ; * * p<0.01 ; * * * p<0.001$ and ${ }^{* * * *} p<0.0001$ for significance. (E, F, G) Correlation between NTRK2 and EGFR expression levels in the TCGA GBM dataset. Pearson correlation coefficients and their $p$ values were calculated using GraphPad prism. Trend lines were determined by the linear regression model. Overall survival probability in a set of 523 samples from the TCGA GBM cohort. (H) all samples and (I) EGFR amplified samples. Patients were grouped according to low or high expression of NTRK2. Survival distribution was estimated according to the Kaplan-Meier method using median cut-off selection and log-rank statistics.

Fig 2 Inhibition of TrkB and EGFR alone or in combination reduces human GBM cell viability. Time course analysis of cell viability, by trypan blue cell counting, were performed after 24,48 and $72 \mathrm{~h}$ of exposure to ANA-12 or AG 1478 exposure in A172 (A, B) and U87MG (C, D) cells. Dose-response curves were evaluated by trypan blue cell counting after treatment with increasing 
concentrations of ANA-12 (1-50 $\mu \mathrm{M})$ or AG $1478(1-30 \mu \mathrm{M})$ for $48 \mathrm{~h}$ in A172 cells $(\mathrm{E}, \mathrm{F})$ and 24 h in U87MG cells $(\mathrm{G}, \mathrm{H})$. The drug vehicles (DMSO or EtOH) served as controls. Dose-response curves after combined treatment with ANA-12 and AG 1478 were evaluated after 48 h of drug exposure in A172 cells (I) and 24 h in U87MG cells (J). Data are expressed by mean \pm SEM and represent three independent experiments $* p<0.05, * * p<0.01$, *** $p<0.001, * * * * p<0.0001$ compared to control cells; \# $p<0.05$ and \#\#\# $p<0.001$ compared to ANA-12; $++p<0.01$ and $+++p<0.001$ compared with AG 1478; one-way ANOVA followed by Tukey tests for multiple comparisons).

Fig 3 Synergistic effect after combined inhibition of TrkB and EGFR in A172 GBM cells. A172 and U87MG cell lines were treated with varying concentrations of ANA-12 and AG 1478 alone or in combination. The IC50-values were calculated from the dose-response curves after different exposure times (48 $\mathrm{h}$ for A172 and $24 \mathrm{~h}$ for U87MG cells) and expressed with their respective 95\% confidence intervals and summarized in the table (A). The combination index (CI) was determined by the method of Chou-Talalay [20] and data are presented as mean \pm SEM (B).

Fig 4 Effects of EGRF and TrkB inhibition on GBM cell cycle. Cells were exposed to ANA-12, AG 1478 or ANA-12 plus AG 1478 for $24 \mathrm{~h}$, and the percentages of cells in G0/G1, S and G2/M phases of the cell cycle were evaluated. Two wells were assigned to each treatment and the experiments were repeated at least three times. Data are presented as mean \pm SEM of the percentage of cells in each phase. $* p<0.05$; ** $p<0.01$; *** $p<0.001$ and $* * * * p<0.0001$ compared to the respective control group, one-way ANOVA followed by the Dunnett test (a,b). 
Fig 5 Inhibition of TrkB and EGFR alone or in combination in a subcutaneous GBM xenograft mouse model. U87MG cells were pretreated in vitro for $24 \mathrm{~h}$ with ANA-12 (13.85 $\mu \mathrm{M}), \mathrm{AG}-1478$ $(13.26 \mu \mathrm{M})$ or ANA-12 plus AG-1478, and the viable cells were injected into the flanks of nude mice (6-7 mice per group) as shown in the schematic drawing (A). Caliper measurements were used to determine the displayed subcutaneous tumor volume. Mice were euthanized and tumors were excised when volume reached approximately $800-1,000 \mathrm{~mm}^{3}$ (B) Tumors were measured every 2 days and volumes were calculated as described in materials and methods section. Tumor growth is represented by tumor volume $\left(\mathrm{mm}^{3}\right)$ at the indicated days; Control $(n=7)$, ANA-12 $(n=$ 8), AG $1478(n=8)$ and ANA-12 plus AG $1478(n=8)$ (C) Tumor growth curve is shown on selected time points of 15, 31 and 45 days to highlight statistical differences (D). Tumor volumes $\left(\mathrm{mm}^{3}\right)$ at the time of tissue harvest. (E) Tumor weight $(\mathrm{mg})$ at the time of tissue harvest are shown in (F) Kaplan-Meier curves presenting percent of mice surviving following tumor implantation. Data are expressed as mean $\pm \operatorname{SEM}(* p<0.05 ; * * p<0.01)$. Statistical analysis was performed using one-way ANOVA followed by Tukey's post-hoc tests. 
MOLE-D-20-00758-R1

Molecular Biology Reports

ORIGINAL ARTICLE

\section{Expression and pharmacological inhibition of TrkB and EGFR in glioblastoma}

\section{Kelly de Vargas Pinheiro ${ }^{1,2} \bullet$ Amanda Thomaz ${ }^{1,2, \star} \bullet$ Bárbara Kunzler Souza ${ }^{1,2,3} \bullet$ Victoria Anne Metcalfe ${ }^{4} \bullet$ Natália Hogetop Freire ${ }^{1} \bullet$ André Tesainer Brunetto ${ }^{1,3} \bullet$ Caroline Brunetto de Farias 1,3 • Mariane Jaeger 1,3 • Victorio Bambini ${ }^{4} \bullet$ Christopher G.S. Smith ${ }^{4} \bullet$ Lisa Shaw ${ }^{4} \bullet$ Rafael Roesler ${ }^{1,2}$}

1 Cancer and Neurobiology Laboratory, Experimental Research Center, Clinical Hospital (CPE-HCPA), Federal University of Rio Grande do Sul, 90035-003 Porto Alegre, RS, Brazil

2 Department of Pharmacology, Institute for Basic Health Sciences, Federal University of Rio Grande do Sul, 90050-170 Porto Alegre, RS, Brazil

3 Children's Cancer Institute, 90620-110 Porto Alegre, RS, Brazil

4 School of Pharmacy and Biomedical Sciences, Faculty of Clinical and Biomedical Sciences, University of Central Lancashire, Preston, Lancashire, PR1 2HE, United Kingdom

Correspondence: Rafael Roesler, Department of Pharmacology, Institute for Basic Health Sciences, Federal University of Rio Grande do Sul, Rua Sarmento Leite, 500 (ICBS, Campus Centro/UFRGS), 90050-170 Porto Alegre, RS, Brazil. E-mail: rafaelroesler@ @cpa.edu.br

* Current address: Division of Biomedical and Life Sciences, Faculty of Health and Medicine, Lancaster University, Lancaster LA 4YG, United Kingdom. 


\section{Abstract}

Background: A member of the Trk family of neurotrophin receptors, tropomyosin receptor kinase B (TrkB, encoded by the NTRK2 gene) is an increasingly important target in various cancer types, including glioblastoma (GBM). EGFR is among the most frequently altered oncogenes in GBM, and EGFR inhibition has been tested as an experimental therapy. Functional interactions between EGFR and TrkB have been demonstrated. In the present study, we investigated the role of TrkB and EGFR, and their interactions, in GBM.

Methods and Results: Analyses of NTRK2 and EGFR gene expression from The Cancer Genome Atlas (TCGA) datasets showed an increase in NTRK2 expression in the proneural subtype of GBM, and a strong correlation between $N T R K 2$ and $E G F R$ expression in glioma $\mathrm{CpG}$ island methylator phenotype (G-CIMP+) samples. We showed that when TrkB and EGFR inhibitors were combined, the inhibitory effect on A172 human GBM cells was more pronounced than when either inhibitor was given alone. When U87MG GBM cells were xenografted into the flank of nude mice, tumor growth was delayed by treatment with TrkB and EGFR inhibitors, given alone or combined, only at specific time points. Intracranial GBM growth in mice was not significantly affected by drug treatments.

Conclusions: Our findings indicate that correlations between NTRK2 and EGFR expression occur in specific GBM subgroups. Also, our results using cultured cells suggest for the first time the potential of combining TrkB and EGFR inhibition for the treatment of GBM.

Keywords Brain tumor $\bullet$ Epidermal growth factor receptor $\bullet$ Glioblastoma $\bullet$ Growth factor receptor $\bullet$ Neurotrophin $\bullet$ Tropomyosin receptor kinase B 


\section{Introduction}

Growth factor receptors constitute many current and potential targets for molecularly specific therapies in cancer. The epidermal growth factor receptor (EGFR), a member of the ERBB family of transmembrane receptor tyrosine kinase (RTK) family, frequently shows gene amplification and activating mutations that contribute to driving the growth of lung and colorectal cancers [1]. EGFR is the target of clinically used small molecule inhibitors including erlotinib and gefitinib and monoclonal antibodies including cetuximab and panitumumab [2].

EGFR is among the most frequently altered oncogenes in glioblastoma (GBM), with 57\% of tumors analyzed by the The Cancer Genome Atlas Research Network (TCGA) showing amplification, mutation, rearrangement, or altered splicing [3]. GBM is the most aggressive type of primary malignant brain tumor. Current treatment based on combining surgical resection followed by radiotherapy and chemotherapy results in a median overall survival of less than 2 years $[4,5]$. To date, clinical trials with EGFR inhibitors in patients with GBM have failed to successfully improve outcomes $[6,7]$. A proposed experimental strategy to reduce resistance and improve effectiveness has been to combine EGFR inhibitors with other targeted agents acting on pathways that crosstalk with EGFR signaling [8, 9].

EGFR has been shown to functionally interact with tropomyosin receptor kinase B (TrkB, encoded by the NTRK2 gene), a member of the Trk family of neurotrophin receptors. Neurotrophins are secreted proteins importantly involved in central nervous system development, neurogenesis, and neuronal survival and plasticity [10]. Increasing evidence indicates that cancers can hijack neurotrophin signaling systems to promote tumor progression and resistance to 
treatment $[9,11]$. In colorectal cancer cells, TrkB activation by its endogenous ligand, brainderived neurotrophic factor (BDNF), promotes resistance against the EGFR inhibitor cetuximab, whereas co-treatment with TrkB and EGFR inhibitors reduce cell viability [12].

GBM tumors express BDNF and TrkB, and TrkB activation enhances the viability of brain tumor stem cells (BTSCs) from human GBMs, whereas its inhibition reduces BTSC growth [13]. TrkB blockade also hinders viability of cultured human GBM cells [14]. BDNF secreted by more differentiated GBM cells supports the growth of TrkB-expressing GBM BTSCs [15]. NTRK gene fusions are currently established as oncogenic drivers of various adult and pediatric tumor types, and larotrectinib, a first-in-class small molecule Trk inhibitor, has received approval for patients with solid tumors harboring $N T R K$ fusions [16, 17]. A gene fusion involving NTRK2 has been found to confer distinctive morphology and an aggressive phenotype in a case of low-grade glioma [18].

Here, we investigated the role of TrkB and EGFR in GBM. First, we show data on the expression of NTRK2 and correlations with EGFR expression in GBM tumors from The Cancer Genome Atlas (TGCA) datasets. We then went on to examine the effects of inhibiting EGFR and TrkB receptors, either alone or in combination, in experimental models of GBM.

\section{Materials and methods}

\section{NTRK2 and EGFR expression profiling in TCGA GBM datasets}


NTRK2 expression levels were examined in previously described The Cancer Genome Atlas (TCGA $n=631$ samples) GBM dataset and TCGA Lower Grade Glioma and Glioblastoma ( $\mathrm{n}=$ 702 samples) dataset. We used the data from gene expression array (platform: AffyU133a, version: 2017-09-08), gene expression RNAseq (platform: IlluminaHiSeq, version: 2017-09-08) and copy number (type: gene-level GISTIC2 threshold, version: 2017-09-08), data were obtained from the University of California-Santa Cruz Xena Public Data Hubs website at http://xena.ucsc.edu/. We analyzed the expression levels of NTRK2 regarding primary disease, primary tumor and recurrent samples, cytosine-phosphate-guanine $(\mathrm{CpG})$ island methylator phenotype (G-CIMP), TCGA molecular subtypes, and the correlation with EGFR expression and amplification. Additionality, we evaluated the correlation between gene expression levels of NTRK2 with patient survival outcomes.

\section{Cell culture}

Human GBM cells A172 and U87MG were obtained from American Type Culture Collection (Rockville, MD, USA) and cultured in Dulbecco's Modified Eagle's Medium (DMEM) low glucose supplemented with $10 \%$ fetal bovine serum (FBS, Gibco® by Thermo Fisher Scientific, Life Technologies, Brazil), $1 \%$ penicillin/streptomycin and $0.1 \%$ fungizone ${ }^{\circledR}(250 \mathrm{mg} / \mathrm{kg}$; Invitrogen Life Technologies, São Paulo, Brazil). Cells were maintained in a humidified atmosphere at $37^{\circ} \mathrm{C}$ and $5 \% \mathrm{CO}_{2}$. 


\section{Drug treatments}

Selective antagonists of TrkB (ANA-12) and EGFR (Tyrphostin AG 1478) were obtained from Sigma Aldrich (St. Louis, MO). ANA-12 was diluted in dimethyl sulfoxide (DMSO) in a stock solution of $6140 \mu \mathrm{M}$ and $\mathrm{AG} 1478$ was diluted in ethanol (EtOH) in a stock solution of $3167 \mu \mathrm{M}$. Other chemical reagents were obtained from qualified national and international suppliers.

\section{Cytotoxicity}

After confluence, A172 and U87MG cells were trypsinized, placed in 96- well plates at an initial density of $5.0 \times 10^{3}$ cells per well and after $24 \mathrm{~h}$ the medium was replaced by increasing concentrations of ANA-12 (0, 1, 10, 20, 30 and $50 \mu \mathrm{M})$, AG- $1478(0,1,5,10,20$ and $30 \mu \mathrm{M})$ and also combinations of both inhibitors for 24,48 or $72 \mathrm{~h}$, while the control cells were maintained in DMSO or $\mathrm{EtOH}$ when the treatments were used alone or a vehicle solution (DMSO plus EtOH) when the treatments were used in combination. In any of the situations the vehicles used did not exceed the concentration of $1 \%(\mathrm{v} / \mathrm{v})$. The effect on cell cytotoxicity was evaluated using the trypan blue exclusion method in the Neubauer chamber $[12,19]$. All assays were performed in triplicate and repeated in three independent sets.

\section{Cell cycle}

To assess cell cycle, GBM cells were cultured in 12-well plates under the same conditions as described above and after $24 \mathrm{~h}$ of exposure to treatments cells were detached, centrifuged and 
washed with PBS twice. The cells were then resuspended in $50 \mu \mathrm{g} / \mathrm{ml}$ propidium iodide (SigmaAldrich, St. Louis, Mo., USA) in $0.1 \%$ Triton X-100 in $0.1 \%$ sodium citrate solution and incubated on ice and protected from light for $15 \mathrm{~min}$. The cells were analyzed by flow cytometry (Attune ${ }^{\circledR}$ Applied Biosystems) and 20,000 events were collected per sample. Three individual experiments were performed.

\section{Ethics statement}

Experimental procedures for the subcutaneous xenograft GBM model were performed in accordance with the Brazilian Guidelines for the Care and Use of Animals in Research and Teaching [DBCA, published by National Council for the Control of Animal Experimentation (CONCEA), and approved by the institutional Animal Care Committee (Comissão de Ética no Uso de Animais CEUA, Hospital de Clínicas de Porto Alegre-HCPA), under protocol number 20160098. Animal experiments for the orthotopic xenograft GBM model were carried out under Animals (Scientific Procedures) Act, 1986 and in accordance to institutional guidelines.

\section{Animals and tumor xenografts}

Balb/c nude mice (6 to 12 weeks old) were obtained from the University Hospital Animal Research Facility (UEA, CPE-HCPA) or from Charles River Laboratories. Animals were housed four per cage and kept under aseptic conditions in ventilated cages, maintained on a $12 \mathrm{~h}$ light/dark cycle at a room temperature of $22 \pm 2{ }^{\circ} \mathrm{C}$. They were allowed ad libitum access to standardized pellet food and water. For the ex-vivo pharmacological inhibition, U87MG cells were cultured in $75 \mathrm{~cm}^{2}$ 
or $175 \mathrm{~cm}^{2}$ culture flasks and treated with $13.85 \mu \mathrm{M}$ of ANA-12, $13.26 \mu \mathrm{M}$ of AG 1478 (alone or in combination) or vehicle (DMSO plus EtOH) for $24 \mathrm{~h}$. A total of $1 \times 10^{6}$ viable cells were processed in serum-free DMEM and diluted 1:1 with Matrigel (Corning, Corning, USA) and then injected subcutaneously (s.c) into the right flank of nude mice (6-8 mice per group). Measurements started five days after cells inoculation, when tumors reached approximately $40-75 \mathrm{~mm}^{3}$. The dimensions, length (L) and width (W), of the resulting tumors were determined every two days using a manual caliper, and the tumor volume $\left(\mathrm{mm}^{3}\right)$ was calculated using the formula: tumor volume $=\left[\right.$ length ${ }^{2} \mathrm{x}$ width/2]. When tumors reached the endpoint $\left(800-1000 \mathrm{~mm}^{3}\right)$ mice were euthanized, and the tumors were excised, measured, and weighed.

For the orthotopic xenograft model, mice were anesthetized with isoflurane (4\% oxygen) and placed in a stereotactic platform. The tops of the heads were disinfected, and a small incision was made in the scalp over the midline. A burr hole was made in the skull to a position $2 \mathrm{~mm}$ posterior and $1.5 \mathrm{~mm}$ lateral to the bregma in the right cerebral hemisphere. Next, mice were injected with 40,000 U87MG cells processed in serum-free DMEM in a volume of $2 \mu 1$ using an injector syringe pump. The burr hole in the skull was closed with sterile bone wax and veterinary tissue glue was used to seal the incision. After surgery, the mice were placed in a recovery cage set to $37^{\circ} \mathrm{C}$ until the animal recovered consciousness. Mice were monitored daily for signs of sickness, pain or weight loss. Seven days followed the surgery the animals were randomized into 4 groups ( $n=5$ per group) to receive intraperitoneal (i.p.) injections for 21 days, and were treated by a blinded investigator with ANA-12 (1 mg/kg/daily plus vehicle for AG1478 every 3 days), AG1478 (10 $\mathrm{mg} / \mathrm{kg}$ every three days plus vehicle for ANA-12 daily), ANA-12 (1 mg/kg daily) plus AG 1478 (10 mg/kg every three days). Control animals received ANA-12 and vehicle (DMSO 2\% in saline solution $0.9 \%$ ) daily and vehicle for AG1478 (DMSO 30 $\mu$ l every three days). Drug doses for in 
vivo experiments were chosen on the basis of previous studies [20 - 24]. Both drugs readily enter

the brain when given systemically in mice or rats $[21,25]$.

\section{Fluorescence imaging}

Administration of 5-aminolevulinic acid (5-ALA), that leads to the synthesis and accumulation of fluorescent protoporphyrin IX (PPIX), has been used with fluorescence-guided surgery to directly visualize high-grade gliomas. After 21 days of treatment, the animals received an i.p. injection of 5-ALA; $50 \mathrm{mg} / \mathrm{kg}$ and after 1 hour the mice were euthanized by cervical dislocation and the brains were removed to be analyzed. The IVIS system was used to record the ex-vivo fluorescent signal from tumors. First, we imaged the whole brains and next we used a brain matrix to cut sequential $1 \mathrm{~mm}$ slices, in order to improve fluorescence detection, and the slices were also imaged. Data acquisition and analysis was performed with Living Image software (Caliper LS living image version: 4.5.2.18424-september 11 2015, camera: IS1621N6980, Andor, iKon). In radiant efficiency mode, the wavelengths for emission and excitation were 620 and 420 respectively, and fixed size of regions of interest (ROIs) were drawn covering the whole tumor. The fluorescent signals (total radiant efficiency/sec) were quantitated by subtracting background fluorescence from tumor signal.

\section{Statistical analysis}

Statistical analysis of gene expression in two or more groups from the TCGA transcriptome datasets were performed using Welch's t-test and Kruskal-Wallis test for significance and Dunn's 
tests for post hoc comparisons, respectively. Correlation analysis were performed by the Pearson correlation method. Survival distribution was estimated according to the Kaplan-Meier method using a median cut-off and log-rank statistics. These analyses were executed using the Graphpad 8.0 software. Significant differences were revealed by $p$ values below 0.05 .

Experimental data were expressed as mean \pm SEM. In vitro and in vivo experiments were analyzed using the GraphPad Prism software package, v. 5.0 (GraphPad, San Diego, CA). The level of significance between different experimental groups was performed using analysis of variance (ANOVA) followed by appropriate post-hoc tests; $p<0.05$ was considered statistically significant. A drug combination analysis was performed based on the $50 \%$ inhibitory concentration (IC50) of the treatments. For calculation of IC50 data were fitted in a dose response curve (Graphpad Prism v. 5.0) using the equation $\mathrm{Y}=100 /\left(1+10^{\wedge}((\mathrm{X}-\log \mathrm{IC} 50))\right)$. The interaction between ANA-12 and AG-1478 was assessed by the combination index method (Cl) [26]. Synergism, addition and antagonism between drug combinations were defined as $\mathrm{CI}<0.9, \mathrm{CI}=$ 0.9-1.1 and CI > 1.1, respectively.

\section{Results}

\section{NTRK2 expression levels are increased in lower grade glioma, proneural GBM subtype and GBM methylated phenotype in GBM patients}

We evaluated TCGA GBM datasets to explore whether NTRK2 expression correlates with EGFR expression, GBM subtype and patient survival. First, we classified TCGA samples by primary disease type between lower grade glioma (LGG) and GBM, based on array data available for 702 
samples. NTRK2 expression was increased in LGG in comparison to GBM samples (Fig. 1A, $p<$ 0.0001). We also evaluated the levels of NTRK2 across normal brain samples, primary and recurrent tumors, however, no statistical differences were observed between these groups (Fig. 1B, $p=0.220$ ). Based on the definition of GBM molecular subtypes, we found that NTRK2 expression was lower in the mesenchymal subtype when compared with neural and proneural subtypes (Fig. 1C, $p<0.01)$. NTRK2 expression was highest in the proneural group in comparison with classical and mesenchymal subtypes (Fig. 1C, $p<0.0001$ ). Given that the proneural group is associated with $I D H$ mutations and $I D H$-mutant gliomas manifest the cytosine-phosphate-guanine (CpG) island methylator phenotype (G-CIMP), we evaluated the expression of NTRK2 regarding the methylation phenotype between G-CIMP ${ }^{+}$and G-CIMP-. We observed an increased expression of NTRK2 in G-CIMP ${ }^{+}$samples (Fig. 1D, $p<0.01$ ), which is consistent with the increased expression in the proneural subtype.

\section{Correlations between NTRK2 and EGFR expression in GBM tumors}

To analyze whether the NTRK2 expression correlates with EGFR levels, we performed correlation analysis across samples registered with TCGA dataset. We detected a weak correlation between NTRK2 and EGFR expression when considering all GBM samples together (Fig. 1E, correlation $=0.1603, p=0.0002$ ) and G-CIMP GBM samples (Fig. $1 \mathrm{G}$, correlation $=0.1869, p=0.0001$ ). A moderate correlation between NTRK2 and EGFR expression was found in G-CIMP+ samples (Fig. $1 \mathrm{~F}$, correlation $=0.3443, p=0.0221)$.

We also determined the relationship between NTRK2 expression and patient overall survival (Fig. 1H), using median of NTRK2 expression as a cutoff between low and high 
expression. We further looked at the effect of NTRK2 expression in patients stratified by EGFR amplification (Fig. 1I). Survival of GBM patients was not significantly different when tumors with high and low NTRK2 expression levels were compared.

Figure 1 should be inserted here

\section{Selective inhibition of TrkB and EGFR decreases GBM cell viability}

To examine the effects of TrkB and EGFR inhibition on cell viability, GBM cells were treated with ANA-12 and AG 1478 alone or in combination and viability was assessed by the trypan blue exclusion method. Time course analysis showed that both single treatments decreased A172 and U87MG cell viability when compared with control cells treated with vehicle $(p<0.001)$. The effect was observed in A172 cells after 48 hours of treatment with ANA-12 at $10 \mu \mathrm{M}$ or AG1478 at $30 \mu \mathrm{M}$ (Fig. 2A, 2B). A similar effect was observed in U87MG cells after 24 hours of treatment with the dose of $10 \mu \mathrm{M}$ of ANA-12 or AG1478 (Fig. 2C, 2D). We also analyzed whether the reduction of cell viability with ANA-12 or AG1478 were dose-dependent. As depicted in Fig. 2, both treatments showed features of dose-dependent effect in A172 and U87MG cells. After time course and dose-response curves analysis, we defined proper doses and time to evaluate the effect of the combination (ANA-12 plus AG1478) on cell viability. When the two drugs were combined the inhibitory effect was more pronounced in A172 cells compared to either IC50-equivalent 
isolated drugs and in the combination of both drugs in higher doses (see Fig. 2I for detailed results and $p$ values for specific comparisons). In contrast, the effect of the combination treatment was not more pronounced than those of each single treatment at equivalent doses in U87MG cells (Fig.2J).

Figure 2 should be inserted here

\section{Pharmacological interactions between TrkB and EGFR inhibitors}

In order to evaluate drug interaction effects, IC50-values were calculated from the effects seen in the cytotoxicity assay (Fig. 3). ANA-12 had IC50 values of 10.0 (7-14) $\mu \mathrm{M}$ and 13.85 (11-17) $\mu \mathrm{M}$ for A172 and U87MG cells, respectively. IC50 values of AG1478 were 20.0 (16-21) $\mu \mathrm{M}$ for A172 cells and 13.26 (11-16) $\mu \mathrm{M}$ for U87MG cells (Fig. 3A). Pharmacological interactions of the combined treatment with ANA-12 and AG1478 were investigated using cytotoxicity as the chosen outcome and evaluated by Chou-Talalay method (Chou and Talalay 1984). Synergism, addition and antagonism for drug combinations was defined as $\mathrm{CI}<0.9, \mathrm{CI}=0.9-1.1$ and $\mathrm{CI}>1.1$, respectively. We observed synergy in A172 cells $(\mathrm{CI}=0.75)$. However, in U87MG cells the inhibitors presented antagonism, as shown by the combination index value of 2.2 (Fig. 3B). 


\section{Figure 3 should be inserted here}

\section{TrkB and EGFR inhibitors induce changes in cell cycle features of GBM cells}

Effects on cell cycle were evaluated by flow cytometry after treatment with ANA-12 and AG 1478 alone or in combination in GBM cells. As shown in Fig. 4, the TrkB inhibitor induced a significant reduction in S phase, which starts at the dose of $10 \mu \mathrm{M}$ and persists at a dose of $20 \mu \mathrm{M}$ in A172 cells (Fig. 4A $p<0.001$ and $p<0.0001$, respectively). An increase in cells in the S phase after TrkB inhibition was observed in U87MG cells at the dose of $50 \mu \mathrm{M}(p<0.05$, Fig. 4D). Treatment with $30 \mu \mathrm{M}$ of AG 1478 significantly increased the number of A172 and U87MG cells in G0/G1 phase when compared with control cells (Fig. 4B, 4E, $p<0.01$ and $p<0.05$, respectively). The combined treatment lead to a combination of effects leading to both accumulation of cells in G0/G1 and reduction of S phase in A172 cells (Fig. 4C $p<0.05$ and $p<0.01$ ). The combined treatment did not cause significant changes in the cell cycle of U87MG cells; however, we could observe a small percentage of cells in Sub-G1 phase when compared with controls (Fig. 4F, $p<0.05$ ).

Figure 4 should be inserted here 


\section{Long-term effects of TrkB and EGFR inhibition in a GBM xenograft mouse model}

To explore the roles of EGFR and TrkB during tumorigenesis, we used a preclinical subcutaneous xenograft GBM model. U87MG cells were treated with ANA-12, AG 1478, ANA-12 plus AG 1478 and DMSO or EtOH. After $24 \mathrm{~h}$, the animals were randomized and viable pre-treated U87MG cells were injected subcutaneously into the right flank of mice (Fig. 5A). Fig. 5B illustrates tumor volume size across different days. Tumor size was significantly different in day 15 in all treatment groups when compared with controls given vehicle. Mice that received cells treated with ANA12, alone or combined with AG 1478, also showed smaller tumors at day 31. The apparent reduction in tumor size in all drug-treated groups compared to controls at day 45 did not reach statistical significance (Fig. 5C). When tumors reached $800-100 \mathrm{~mm}^{3}$ the mice were euthanized, and the tumors were excised, and weight and volume were determined. Ex-vivo tumor analysis showed an apparent reduction in tumor volume when compared treatment groups with control, however, these differences did not reach statistical significance (Fig. 5D). Moreover, there were no statistically significant differences among groups regarding tumor weight (Fig. 5E). We also evaluated possible differences in survival comparing treatment groups with control group. Although the median survival days of the control group (38 days) was lower when compared to treatment groups (ANA-12, 45 days; AG 1478, 41 days; ANA-12+AG 1478, 44 days), no statistically differences were observed (Fig. 5F). 
Figure 5 should be inserted here

\section{Lack of effect of combined TrkB and EGFR inhibition on intracranial GBM tumor growth}

We tested the hypothesis that the combined inhibition of TrkB plus EGFR would inhibit the growth of intracranial GBM in mice. Seven days after inoculation of U87MG cells, mice were randomized to receive i.p. injections in a period of 21 days with ANA-12 $(1 \mathrm{mg} / \mathrm{kg}$ daily plus vehicle every 3 days), AG1478 (10 mg/kg every three days plus vehicle daily), ANA-12 (1 mg/kg daily) plus AG $1478(10 \mathrm{mg} / \mathrm{kg}$ every three days) and vehicle daily. During the treatment period, mice were monitored daily for any signs of sickness, pain or weight loss. The tumor growth was analyzed by ex-vivo brain fluorescent imaging of the different groups using the IVIS system after 29 days after cell inoculation. Tumor fluorescence did not reveal a significant difference among groups $(p=$ 0.771; Suppl. Fig. S1).

\section{Discussion}

Gene expression analysis in GBM tumor datasets showed an increased NTRK2 expression in proneural, G-CIMP ${ }^{+}$GBMs. Interestingly, significant correlations between NTRK2 and EGFR 
expression levels were found in GBM, particularly in G-CIMP+ tumors. Previous analyses of TCGA GBMs have shown that G-CIMP+ glioblastomas presented reduced mRNA levels for EGFR due to epigenetic regulation [27]. The proneural G-CIMP phenotype confers a survival advantage for GBM patients [3], and its possible relationship with NTRK2 expression revealed here warrants further exploration.

One of the main findings in the present study was that the combined inhibition of TrkB and EGFR was more pronounced than either treatment given alone in impairing A172 GBM cell viability. This result is consistent with the view that TrkB inhibition may sensitize cancer cells to the effects of EGFR inhibitors [28]. ANA-12, originally developed as an experimental antidepressant, selectively and efficiently inhibits TrkB by binding to both low- and high-affinity sites on the receptor extracellular domain [21]. AG 1478 is a selective EGFR inhibitor that shares a structural quinazoline main chain with the clinically used EGFR inhibitors gefitinib and erlotinib [20]. The results observed with these two small-molecule compounds in two different mouse GBM xenograft models were less clear. When cells were pretreated with drug treatments before being xenografted into the flanks of nude mice, treatments were able to slow tumor growth only at specific time points (15 and 31 days after cell inoculation), but drug-treated tumors were able to reach sizes comparable to controls by the end of the follow-up period. In addition, treatments did not significantly change tumor progression assessed by fluorescence in mice receiving GBM cells intracranially followed by systemic drug treatments. Given the potency of ANA-12 and AG1478 inhibition of cell viability in vitro, we expected to observe pronounced drug effects in in vivo models. A possible limitation was measuring fluorescence only at the end of treatment rather than at different time points during treatment. Importantly, EGFR may have a dual role, contributing to tumor progression but also conferring increased DNA damage response and high sensitivity to the 
inhibitor talazoparib [29]. Thus, differential roles of EGFR signaling could occur under the different experimental conditions we used (for example, regulation by the tumor microenvironment in in vivo assays), resulting in contrasting findings. The lack of effects may also be related to the choice of drug doses in our experiments. The drug doses and treatment regimens we used for in vivo experiments were based on previous studies that used xenograft models of GBM and other cancer types [22, 24, 25]. It is still possible that, as suggested by our results shown in Fig. 3, the two drugs used show antagonistic activity in U87MG cells. Another point worth mentioning is that, together, the results obtained in our in vitro and flank xenograft experiments might suggest that TrkB and EGFR inhibition can delay GBM growth in the short-term, but not after longer delays, when tumors are able to recover full growth.

One issue worthy discussing is the opposite pattern of effects on cytotoxity between the two cell lines. Pharmacological interaction analysis showed synergism in A172 cells but antagonism in U87 MG cells. In terms of genetic profiles, both A172 and U87 MG cells are mutant for both CDKN2A and PTEN. However, U87 MG cells express only wild-type EGFR, whereas A172 cells also express TDM/18-26 mutant EGFR [30, 31]. This biological difference might be crucial to explain the contrasting effects we observed between cell lines. In addition, we have previously observed, in experiments using medulloblastoma cells, that BDNF/TrkB signaling may have opposite effects on cell viability, so TrkB activation can either induce or prevent cytotoxicity depending on drug combinations and experimental conditions [32 - 34]. In fact, BDNF can play opposite actions depending on changes in cellular context. These differential effects may involve distinct isoforms of TrkB expressed in different cell tumor types [34]. This dependency on cellular environment might also be related to the switch from synergism to antagonism we observed when TrkB inhibition was combined with EGFR inhibitor. GBM tumors interact in complex ways with 
a microenvironment consisting of glial, endothelial, and immune cells. Several signaling molecules, including growth factors, mediate intercellular communication between GBM cells and cells composing the microenvironment [35 - 37]. It is thus possible that the interactions between receptors such as TrkB and EGFR in GBM, as well as the effects of receptor inhibitors, are modulated by biochemical signals from the microenvironment. It is also possible that inhibitors interact directly with receptors on cells in the microenvironment, resulting in changes of drug responses in vivo compared to in vitro models. These are complex issues that warrant further research in the field of targeted therapies for GBM.

GBM differentiated cells have been shown to secrete BDNF to stimulate TrkB in GBM stem cells and induce them to secrete nerve growth factor inducible (VGF), a neuropeptide that promotes survival and growth of GBM stem-like and differentiated cells [15]. TrkB knockdown or pharmacological inhibition of TrkB hinders BDNF-dependent GBM stem-like cell growth [13]. TrkB-containing exosomes promote the transfer of aggressiveness between GBM cells [38]. EGFR inhibition has been proposed as a therapeutic strategy in GBM and has been tested in preclinical [39 - 41] and clinical [42, 43] studies, with mixed results. One previous study examined the interaction between TrkB and EGFR in experimental GBM and showed that stimulation of neurotrophin signaling can overcome the inhibitory effects of EGFR inhibition on GBM cell growth [13]. The present study is the first one to verify whether the combined inhibition of TrkB and EGFR may effectively reduce GBM growth.

In summary, analysis of TCGA tumors showed that correlations between NTRK2 and EGFR expression can be observed in GBM, and the role of TrkB and EGFR in the proneural, G$\mathrm{CIMP}^{+}$subtype of GBM should be further investigated by future studies. In addition, our results 
using cultured cells indicate for the first time the potential of combining TrkB and EGFR inhibition for the treatment of GBM, however we could not observe pronounced effects in vivo.

Acknowledgements This article has been previously published as a preprint at https://www.biorxiv.org/content/10.1101/2020.02.03.932608v1.

Funding This research was supported by the National Council for Scientific and Technological Development (CNPq; grant numbers 409287/2016-4 and 305647/2019-9 to R.R.); the Coordination for the Improvement of Higher Education Personnel (CAPES); the Children's Cancer Institute (ICI); the Clinical Hospital institutional research fund (FIPE/HCPA); the University of Central Lancashire; InbetweenEars; and the Brain Tumour North West Research Consortium.

Disclosure of potential conflicts of interest The authors declare that they have no competing interests related to the contents of this manuscript.

Research involving human participants and/or animals Not applicable.

Informed consent Not applicable. 


\section{References}

1. Mitsudomi T, Yatabe Y (2010) Epidermal growth factor receptor in relation to tumor development: EGFR gene and cancer. FEBS J 277(2): 301-308

2. Arteaga CL, Engelman JA (2014) ERBB receptors: from oncogene discovery to basic science to mechanism-based cancer therapeutics. Cancer Cell 25(3): 282-303

3. Brennan CW, Verhaak RG, McKenna A, Campos B, Noushmehr H, Salama SR, Zheng S, Chakravarty D, Sanborn JZ, Berman SH, Beroukhim R, Bernard B, Wu CJ, Genovese G, Shmulevich I, Barnholtz-Sloan J, Zou L, Vegesna R, Shukla SA, Ciriello G, Yung WK, Zhang W, Sougnez C, Mikkelsen T, Aldape K, Bigner DD, Van Meir EG, Prados M, Sloan A, Black KL, Eschbacher J, Finocchiaro G, Friedman W, Andrews DW, Guha A, Iacocca M, O'Neill BP, Foltz G, Myers J, Weisenberger DJ, Penny R, Kucherlapati R, Perou CM, Hayes DN, Gibbs R, Marra M, Mills GB, Lander E, Spellman P, Wilson R, Sander C, Weinstein J, Meyerson M, Gabriel S, Laird PW, Haussler D, Getz G, Chin L; TCGA Research Network (2013) The somatic genomic landscape of glioblastoma. Cell 155(2): $462-477$

4. Stupp R, Mason WP, van den Bent MJ, Weller M, Fisher B, Taphoorn MJ, Belanger K, Brandes AA, Marosi C, Bogdahn U, Curschmann J, Janzer RC, Ludwin SK, Gorlia T, Allgeier A, Lacombe D, Cairncross JG, Eisenhauer E, Mirimanoff RO; European Organisation for Research and Treatment of Cancer Brain Tumor and Radiotherapy Groups; National Cancer Institute of Canada Clinical Trials Group (2005) Radiotherapy 
plus concomitant and adjuvant temozolomide for glioblastoma. N Engl J Med 352(10): 987-996

5. Wen PY, Kesari S (2008) Malignant gliomas in adults. N Engl J Med 359(5): 492-507

6. van den Bent MJ, Brandes AA, Rampling R, Kouwenhoven MC, Kros JM, Carpentier AF, Clement PM, Frenay M, Campone M, Baurain JF, Armand JP, Taphoorn MJ, Tosoni A, Kletzl H, Klughammer B, Lacombe D, Gorlia T (2009) Randomized phase II trial of erlotinib versus temozolomide or carmustine in recurrent glioblastoma: EORTC brain tumor group study 26034. J Clin Oncol 27(8): 1268-1274

7. Vivanco I, Robins HI, Rohle D, Campos C, Grommes C, Nghiemphu PL, Kubek S, Oldrini B, Chheda MG, Yannuzzi N, Tao H, Zhu S, Iwanami A, Kuga D, Dang J, Pedraza A, Brennan CW, Heguy A, Liau LM, Lieberman F, Yung WK, Gilbert MR, Reardon DA, Drappatz J, Wen PY, Lamborn KR, Chang SM, Prados MD, Fine HA, Horvath S, Wu N, Lassman AB, DeAngelis LM, Yong WH, Kuhn JG, Mischel PS, Mehta MP, Cloughesy TF, Mellinghoff IK (2012) Differential sensitivity of glioma- versus lung cancer-specific EGFR mutations to EGFR kinase inhibitors. Cancer Discov 2(5): 458-471

8. Keller S, Schmidt MHH (2017) EGFR and EGFRvIII promote angiogenesis and cell invasion in glioblastoma: Combination therapies for an effective treatment. Int J Mol Sci 18(6): E129

9. Roesler R, Brunetto AT, Abujamra AL, de Farias CB, Brunetto AL, Schwartsmann G (2010) Current and emerging molecular targets in glioma. Expert Rev Anticancer Ther 10(11): 1735-1751 
10. Park H., Poo MM (2013) Neurotrophin regulation of neural circuit development and function. Nat Rev Neurosci 14(1): 7-23

11. Thiele CJ, Li Z, McKee AE (2009) On Trk--the TrkB signal transduction pathway is an increasingly important target in cancer biology. Clin Cancer Res 15(19): 5962-5967

12. de Farias CB, Heinen TE, dos Santos RP, Abujamra AL, Schwartsmann G, Roesler R (2012) BDNF/TrkB signaling protects HT-29 human colon cancer cells from EGFR inhibition. Biochem Biophys Res Commun 425(2): 328-332

13. Lawn S, Krishna N, Pisklakova A, Qu X, Fenstermacher DA, Fournier M, Vrionis FD, Tran N, Chan JA, Kenchappa RS, Forsyth PA (2015) Neurotrophin signaling via TrkB and TrkC receptors promotes the growth of brain tumor-initiating cells. J Biol Chem 290(6): 3814-3824

14. Pinheiro KV, Alves C, Buendia M, Gil MS, Thomaz A, Schwartsmann G, de Farias CB, Roesler R (2017) Targeting tyrosine receptor kinase B in gliomas. Neuro Oncol 19(1): 138139

15. Wang X, Prager BC, Wu Q, Kim LJY, Gimple RC, Shi Y, Yang K, Morton AR, Zhou W, Zhu Z, Obara EAA, Miller TE, Song A, Lai S, Hubert CG, Jin X, Huang Z, Fang X, Dixit D, Tao W, Zhai K, Chen C, Dong Z, Zhang G, Dombrowski SM, Hamerlik P, Mack SC, Bao S, Rich JN (2018) Reciprocal signaling between glioblastoma stem cells and differentiated tumor cells promotes malignant progression. Cell Stem Cell 22(4): 514528.e5

16. Cocco E, Scaltriti M, Drilon A (2018) NTRK fusion-positive cancers and TRK inhibitor therapy. Nat Rev Clin Oncol 15(12): 731-747 
17. Drilon A, Laetsch TW, Kummar S, DuBois SG, Lassen UN, Demetri GD, Nathenson M, Doebele RC, Farago AF, Pappo AS, Turpin B, Dowlati A, Brose MS, Mascarenhas L, Federman N, Berlin J, El-Deiry WS, Baik C, Deeken J, Boni V, Nagasubramanian R, Taylor M, Rudzinski ER, Meric-Bernstam F, Sohal DPS, Ma PC, Raez LE, Hechtman JF, Benayed R, Ladanyi M, Tuch BB, Ebata K, Cruickshank S, Ku NC, Cox MC, Hawkins DS, Hong DS, Hyman DM (2018) Efficacy of larotrectinib in TRK fusion-positive cancers in adults and children. N Engl J Med 378(8): 731-739

18. Jones KA, Bossler AD, Bellizzi AM, Snow AN (2019) BCR-NTRK2 fusion in a low-grade glioma with distinctive morphology and unexpected aggressive behavior. Cold Spring Harb Mol Case Stud 5(2). pii: a003855

19. Thomaz A, Jaeger M, Buendia M, Bambini-Junior V, Gregianin LJ, Brunetto AL, Brunetto AT, de Farias CB, Roesler R (2016) BDNF/TrkB signaling as a potential novel target in pediatric brain tumors: Anticancer activity of selective TrkB inhibition in medulloblastoma cells. J Mol Neurosci 59(3): 326-333

20. Ellis AG, Doherty MM, Walker F, Weinstock J, Nerrie M, Vitali A, Murphy R, Johns TG, Scott AM, Levitzki A, McLachlan G, Webster LK, Burgess AW, Nice EC (2006) Preclinical analysis of the analinoquinazoline AG1478, a specific small molecule inhibitor of EGF receptor tyrosine kinase. Biochem Pharmacol 71(10): 1422-1434

21. Cazorla M, Prémont J, Mann A, Girard N, Kellendonk C, Rognan D (2011) Identification of a low-molecular weight TrkB antagonist with anxiolytic and antidepressant activity in mice. J Clin Invest 121(5): 1846-1857 
22. Yu Y, Zhang M, Zhang X, Cai Q, Hong S, Jiang W, Xu C (2014) Synergistic effects of combined platelet-activating factor receptor and epidermal growth factor receptor targeting in ovarian cancer cells. J Hematol Oncol 7: 39

23. Li W, Fang Q, Zhong P, Chen L, Wang L, Zhang Y, Wang J, Li X, Wang Y, Wang J, Liang G (2016) EGFR inhibition blocks palmitic acid-induced inflammation in cardiomyocytes and prevents hyperlipidemia-induced cardiac injury in mice. Sci Rep 6: 24580

24. Thomaz A, Pinheiro KV, Souza BK, Gregianin L, Brunetto AL, Brunetto AT, de Farias CB, Jaeger MDC, Ramaswamy V, Nör C, Taylor MD, Roesler R (2019) Antitumor activities and cellular changes induced by TrkB inhibition in medulloblastoma. Front Pharmacol 10: 698

25. Nagane M, Narita Y, Mishima K, Levitzki A, Burgess AW, Cavenee WK, Huang HJ (2001) Human glioblastoma xenografts overexpressing a tumor-specific mutant epidermal growth factor receptor sensitized to cisplatin by the AG1478 tyrosine kinase inhibitor. J Neurosurg 95: 472-479

26. Chou TC, Talalay P (1984) Quantitative analysis of dose-effect relationships: the combined effects of multiple drugs or enzyme inhibitors. Adv Enzyme Regul 22: 27-55.

27. Li J, Taich ZJ, Goyal A, Gonda D, Akers J, Adhikari B, Patel K, Vandenberg S, Yan W, Bao Z, Carter BS, Wang R, Mao Y, Jiang T, Chen CC (2014) Epigenetic suppression of EGFR signaling in G-CIMP+ glioblastomas. Oncotarget 5(17): 7342-7356

28. Roesler R, de Farias CB, Abujamra AL, Brunetto AL, Schwartsmann G (2011) BDNF/TrkB signaling as an anti-tumor target. Expert Rev Anticancer Ther 11(10): 14731475 
29. Wu S, Gao F, Zheng S, Zhang C, Martinez-Ledesma E, Ezhilarasan R, Ding J, Li X, Feng N, Multani A, Sulman EP, Verhaak RG, de Groot JF, Heffernan TP, Yung WKA, Koul D (2020) EGFR amplification induces increased DNA damage response and renders selective sensitivity to Talazoparib (PARP inhibitor) in glioblastoma. Clin Cancer Res 26(6): 13951407

30. Ciesielski MJ, Fenstermaker RA (2000) Oncogenic epidermal growth factor receptor mutants with tandem duplication: gene structure and effects on receptor function. Oncogene 19(6): 810-820

31. Carrasco-García E, Saceda M, Grasso S, Rocamora-Reverte L, Conde M, Gómez-Martínez A, García-Morales P, Ferragut JA, Martínez-Lacaci I (2011) Small tyrosine kinase inhibitors interrupt EGFR signaling by interacting with erbB3 and erbB4 in glioblastoma cell lines. Exp Cell Res 317(10): 1476-1489

32. Schmidt AL, de Farias CB, Abujamra AL, Kapczinski F, Schwartsmann G, Brunetto AL, Roesler R (2010) BDNF and PDE4, but not the GRPR, regulate viability of human medulloblastoma cells. J Mol Neurosci 40: 303-310

33. Nör C, de Farias CB, Abujamra AL, Schwartsmann G, Brunetto AL, Roesler R (2011) The histone deacetylase inhibitor sodium butyrate in combination with brain-derived neurotrophic factor reduces the viability of DAOY human medulloblastoma cells. Childs Nerv Syst 27: 897-901

34. Radin DP, Patel P (2017) BDNF: an oncogene or tumor suppressor? Anticancer Res 37(8): 3983-3990 
35. de Almeida Sassi F, Lunardi Brunetto A, Schwartsmann G, Roesler R, Abujamra AL (2012) Glioma revisited: from neurogenesis and cancer stem cells to the epigenetic regulation of the niche. J Oncol 2012: 537861

36. Perus LJM, Walsh LA (2019) Microenvironmental heterogeneity in brain malignancies. Front Immunol 10: 2294

37. Simon T, Jackson E, Giamas G (2020) Breaking through the glioblastoma microenvironment via extracellular vesicles. Oncogene 39: 4477-4490

38. Pinet S, Bessette B, Vedrenne N, Lacroix A, Richard L, Jauberteau MO, Battu S, Lalloué F (2016) TrkB-containing exosomes promote the transfer of glioblastoma aggressiveness to YKL-40-inactivated glioblastoma cells. Oncotarget 7(31): 50349-50364

39. Parker JJ, Dionne KR, Massarwa R, Klaassen M, Foreman NK, Niswander L, Canoll P, Kleinschmidt-Demasters BK, Waziri A (2013) Gefitinib selectively inhibits tumor cell migration in EGFR-amplified human glioblastoma. Neuro Oncol 15(8): 1048-1057

40. Zahonero C, Aguilera P, Ramírez-Castillejo C, Pajares M, Bolós MV, Cantero D, PerezNuñez A, Hernández-Laín A, Sánchez-Gómez P, Sepúlveda JM (2015) Preclinical test of dacomitinib, an irreversible EGFR inhibitor, confirms its effectiveness for glioblastoma. Mol Cancer Ther 14(7): 1548-1558

41. Buendia Duque M, Pinheiro KV, Thomaz A, da Silva CA, Freire NH, Brunetto AT, Schwartsmann G, Jaeger M, de Farias CB, Roesler R (2019) Combined inhibition of HDAC and EGFR reduces viability and proliferation and enhances STAT3 mRNA expression in glioblastoma cells. J Mol Neurosci 68(1): 49-57 
42. Sepúlveda-Sánchez JM, Vaz MÁ, Balañá C, Gil-Gil M, Reynés G, Gallego Ó, MartínezGarcía M, Vicente E, Quindós M, Luque R, Ramos A, Ruano Y, Pérez-Segura P, Benavides M, Sánchez-Gómez P, Hernández-Laín A (2017) Phase II trial of dacomitinib, a pan-human EGFR tyrosine kinase inhibitor, in recurrent glioblastoma patients with EGFR amplification. Neuro Oncol 19(11): 1522-1531

43. Makhlin I, Salinas RD, Zhang D, Jacob F, Ming GL, Song H, Saxena D, Dorsey JF, Nasrallah MP, Morrissette JJ, Binder ZA, O'Rourke DM, Desai AS, Brem S, Bagley SJ (2019) Clinical activity of the EGFR tyrosine kinase inhibitor osimertinib in EGFR-mutant glioblastoma. CNS Oncol 8(3): CNS43 


\section{Legends for figures}

Fig 1 NTRK2 expression and its correlation with EGFR expression levels in TCGA GBM datasets. Transcript levels of NTRK2 were examined in previously described transcriptome datasets from the TCGA GBM dataset ( $n=631$ samples) and the TCGA Lower Grade Glioma (LGG) and GBM ( $n=702$ samples) dataset. (A) Expression levels of NTRK2 in LGG and GBM patient cohorts. (B) Normal brain, primary and recurrent GBM samples. (C) GBM subtypes. (D) cytosine-phosphateguanine $(\mathrm{CpG})$ island methylator phenotype (G-CIMP). Data was presented in violin plot format as log2-transformed signal intensity and statistical analyses were performed using Kruskal-Wallis test followed by Dunn's post hoc tests, ${ }^{*} p<0.05 ; * * p<0.01 ; * * * p<0.001$ and $* * * * p<0.0001$ for significance. (E, F, G) Correlation between NTRK2 and EGFR expression levels in the TCGA GBM dataset. Pearson correlation coefficients and their $p$ values were calculated using GraphPad prism. Trend lines were determined by the linear regression model. Overall survival probability in a set of 523 samples from the TCGA GBM cohort. (H) all samples and (I) EGFR amplified samples. Patients were grouped according to low or high expression of NTRK2. Survival distribution was estimated according to the Kaplan-Meier method using median cut-off selection and log-rank statistics.

Fig 2 Inhibition of TrkB and EGFR alone or in combination reduces human GBM cell viability. Time course analysis of cell viability, by trypan blue cell counting, were performed after 24, 48 and $72 \mathrm{~h}$ of exposure to ANA-12 or AG 1478 exposure in A172 (A, B) and U87MG (C, D) cells. Dose-response curves were evaluated by trypan blue cell counting after treatment with increasing 
concentrations of ANA-12 (1-50 $\mu \mathrm{M})$ or AG $1478(1-30 \mu \mathrm{M})$ for $48 \mathrm{~h}$ in A172 cells $(\mathrm{E}, \mathrm{F})$ and 24 h in U87MG cells $(\mathrm{G}, \mathrm{H})$. The drug vehicles (DMSO or EtOH) served as controls. Dose-response curves after combined treatment with ANA-12 and AG 1478 were evaluated after 48 h of drug exposure in A172 cells (I) and $24 \mathrm{~h}$ in U87MG cells (J). Data are expressed by mean \pm SEM and represent three independent experiments $* p<0.05, * * p<0.01$, *** $p<0.001, * * * * p<0.0001$ compared to control cells; \# $p<0.05$ and \#\#\# $p<0.001$ compared to ANA-12; $++p<0.01$ and $+++p<0.001$ compared with AG 1478; one-way ANOVA followed by Tukey tests for multiple comparisons).

Fig 3 Synergistic effect after combined inhibition of TrkB and EGFR in A172 GBM cells. A172 and U87MG cell lines were treated with varying concentrations of ANA-12 and AG 1478 alone or in combination. The IC50-values were calculated from the dose-response curves after different exposure times (48 $\mathrm{h}$ for A172 and $24 \mathrm{~h}$ for U87MG cells) and expressed with their respective 95\% confidence intervals and summarized in the table (A). The combination index (CI) was determined by the method of Chou-Talalay [20] and data are presented as mean \pm SEM (B).

Fig 4 Effects of EGRF and TrkB inhibition on GBM cell cycle. Cells were exposed to ANA-12, AG 1478 or ANA-12 plus AG 1478 for $24 \mathrm{~h}$, and the percentages of cells in G0/G1, S and G2/M phases of the cell cycle were evaluated. Two wells were assigned to each treatment and the experiments were repeated at least three times. Data are presented as mean \pm SEM of the percentage of cells in each phase. $* p<0.05$; ** $p<0.01$; *** $p<0.001$ and $* * * * p<0.0001$ compared to the respective control group, one-way ANOVA followed by the Dunnett test (a,b). 
Fig 5 Inhibition of TrkB and EGFR alone or in combination in a subcutaneous GBM xenograft mouse model. U87MG cells were pretreated in vitro for $24 \mathrm{~h}$ with ANA-12 (13.85 $\mu \mathrm{M})$, AG-1478 $(13.26 \mu \mathrm{M})$ or ANA-12 plus AG-1478, and the viable cells were injected into the flanks of nude mice (6-7 mice per group) as shown in the schematic drawing (A). Caliper measurements were used to determine the displayed subcutaneous tumor volume. Mice were euthanized and tumors were excised when volume reached approximately $800-1,000 \mathrm{~mm}^{3}$ (B) Tumors were measured every 2 days and volumes were calculated as described in materials and methods section. Tumor growth is represented by tumor volume $\left(\mathrm{mm}^{3}\right)$ at the indicated days; Control $(n=7)$, ANA-12 $(n=$ 8), AG $1478(n=8)$ and ANA-12 plus AG $1478(n=8)$ (C) Tumor growth curve is shown on selected time points of 15, 31 and 45 days to highlight statistical differences (D). Tumor volumes $\left(\mathrm{mm}^{3}\right)$ at the time of tissue harvest. (E) Tumor weight $(\mathrm{mg})$ at the time of tissue harvest are shown in (F) Kaplan-Meier curves presenting percent of mice surviving following tumor implantation. Data are expressed as mean $\pm \operatorname{SEM}(* p<0.05 ; * * p<0.01)$. Statistical analysis was performed using one-way ANOVA followed by Tukey's post-hoc tests. 